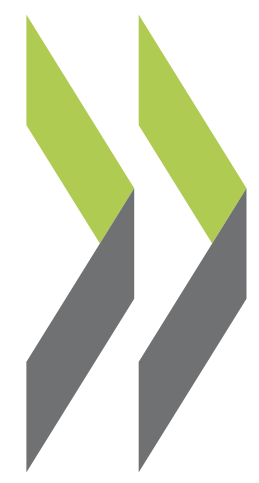

OECD Economics Department Working Papers No. 1490

$$
\begin{array}{r}
\text { The Sustainable } \\
\text { Management } \\
\text { of a Productive Natural } \\
\text { Capital }
\end{array}
$$$$
\text { Julien Xavier Daubanes }
$$ 
ECONOMICS DEPARTMENT

THE SUSTAINABLE MANAGEMENT OF A PRODUCTIVE NATURAL

\section{CAPITAL}

ECONOMICS DEPARTMENT WORKING PAPERS No. 1490

\section{By Julien Xavier Daubanes}

OECD Working Papers should not be reported as representing the official views of the OECD or of its member countries. The opinions expressed and arguments employed are those of the author(s).

Authorised for publication by Isabell Koske, Deputy Director, Country Studies Branch, Economics Department.

All Economics Department Working Papers are available at www.oecd.org/eco/workingpapers.

\section{JT03434621}


OECD Working Papers should not be reported as representing the official views of the OECD or of its member countries. The opinions expressed and arguments employed are those of the author(s).

Working Papers describe preliminary results or research in progress by the author(s) and are published to stimulate discussion on a broad range of issues on which the OECD works.

Comments on Working Papers are welcomed, and may be sent to OECD Economics Department, 2 rue André Pascal, 75775 Paris Cedex 16, France, or by e-mail to eco.contact@oecd.org.

All Economics Department Working Papers are available at www.oecd.org/eco/workingpapers.

This document and any map included herein are without prejudice to the status of or sovereignty over any territory, to the delimitation of international frontiers and boundaries and to the name of any territory, city or area.

The statistical data for Israel are supplied by and under the responsibility of the relevant Israeli authorities. The use of such data by the OECD is without prejudice to the status of the Golan Heights, East Jerusalem and Israeli settlements in the West Bank under the terms of international law.

On 3 May 2018, the OECD Council invited Lithuania to become a Member. At the time of preparation the deposit of Lithuania's instrument of accession to the OECD Convention was pending and therefore Lithuania does not appear in the list of OECD Members and is not included in the OECD zone aggregates.

On 25 May 2018, the OECD Council invited Colombia to become a Member. At the time of preparation the deposit of Colombia's instrument of accession to the OECD Convention was pending and therefore Colombia does not appear in the list of OECD Members and is not included in the OECD zone aggregates.

\section{(C) OECD (2018)}

You can copy, download or print OECD content for your own use, and you can include excerpts from OECD publications, databases and multimedia products in your own documents, presentations, blogs, websites and teaching materials, provided that suitable acknowledgment of OECD as source and copyright owner is given. All requests for commercial use and translation rights should be submitted to rights@oecd.org 


\section{Abstract/Résumé \\ The Sustainable Management of a Productive Natural Capital}

This paper examines an industry whose economic activity uses a natural capital on which its profit also relies. When such a productive natural capital has a limited capacity to recover from its exploitation, a free market tends to over-exploit it, calling for public intervention. The analysis is relevant, among other examples, to the case of nature- based tourism. I study the sustainable management of a productive natural capital: the conditions under which its exploitation generates maximum long-run social benefits; the various ways in which a regulator can implement such an exploitation; the rent that it generates for the industry; the effect of social discounting and operators' short-termism, etc. Particular attention is given to situations in which the regulator gives more importance to the industry than it does to consumers, as when consumers are foreigners or when the industry generates needed tax revenues. In those contexts, I find that the industry should make more efforts of conservation, rather than less.

JEL Codes: Q2; L1; H5.

Keywords: Renewable natural resources; Over-exploitation; Optimal regulation; Pro- industry regulation; Public revenue needs; Optimum taxation; Nature-based tourism.

\section{La gestion durable du capital naturel productif}

Nous étudions dans ce document un secteur dont l'activité économique se fonde sur un capital naturel sur lequel reposent également ses bénéfices. Lorsqu'un tel capital naturel productif se caractérise par une capacité limitée de régénération à la suite de son exploitation, il tend à être surexploité dans un contexte de libre jeu du marché, ce qui rend nécessaire l'intervention des pouvoirs publics. Cela vaut, entre autres exemples, pour le tourisme axé sur la nature. Nous étudions la gestion durable d'un capital naturel productif, c'est-à-dire les conditions dans lesquelles les retombées sociales positives à long terme de son exploitation sont maximales, les différentes façons dont un organisme de régulation peut encadrer cette exploitation, la rente qui en découle pour le secteur concerné, les effets de l'application d'un taux d'actualisation social et du court-termisme des exploitants, etc. Nous prêtons une attention toute particulière aux situations dans lesquelles l'organisme de régulation accorde davantage d'importance au secteur qu'aux consommateurs, notamment lorsque les consommateurs sont des étrangers ou lorsque le secteur permet aux autorités de collecter des recettes fiscales dont elles ont besoin. Dans ces contextes, nous parvenons à la conclusion que le secteur devrait renforcer ses efforts de préservation de la nature, et non les réduire.

JEL Codes: Q2; L1; H5.

Mots clés : ressources naturelles renouvelables ; surexploitation ; réglementation optimale ; réglementation favorable aux entreprises ; besoins de recettes publiques ; fiscalité optimale ; tourisme axé sur la nature. 


\section{Table of contents}

The Sustainable Management of a Productive Natural Capital ............................................................ 6

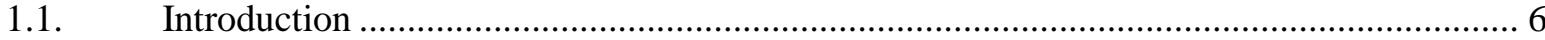

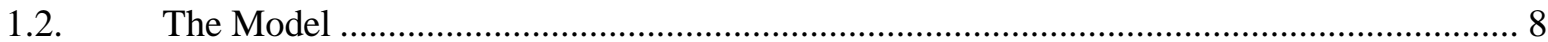

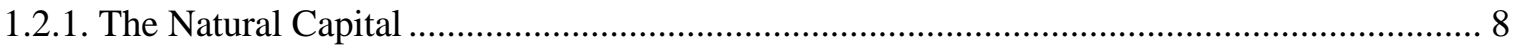

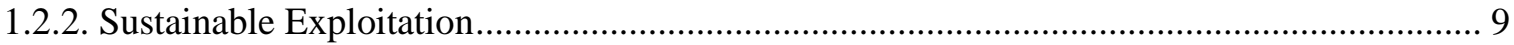

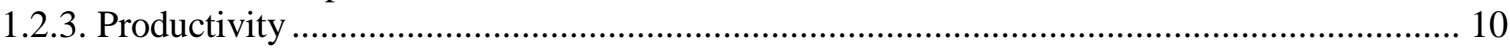

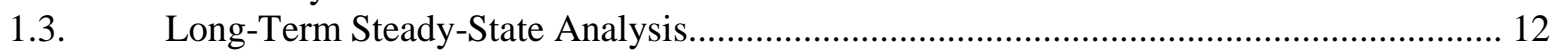

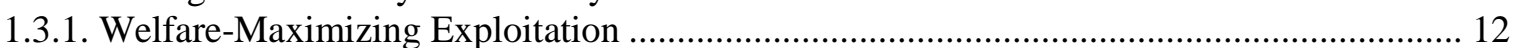

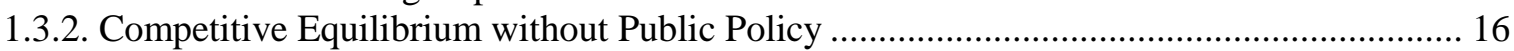

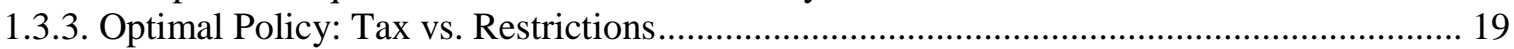

1.4. Monopoly Power, Industry-Oriented Regulation, and Public Finance.............................. 21

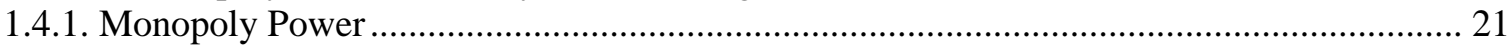

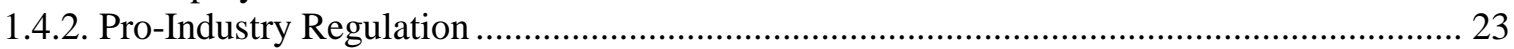

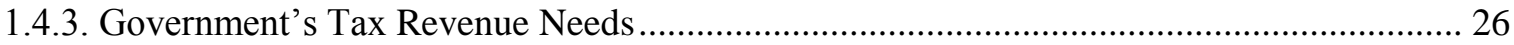

1.5. Short-Run Transitional Dynamics, Long-Term Stability, and Discounting ...................... 28

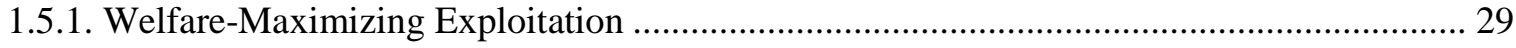

1.5.2. Competitive Equilibrium without Public Policy ................................................................. 31

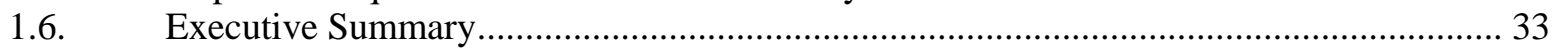

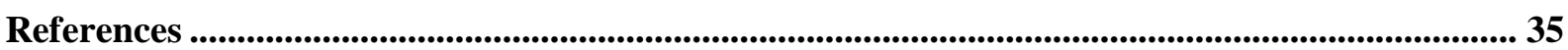

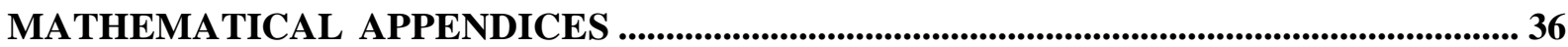

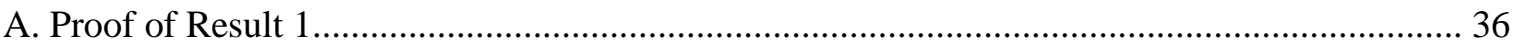

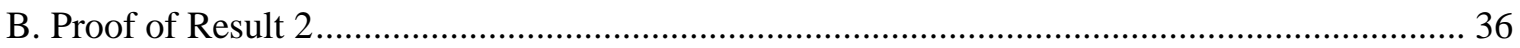

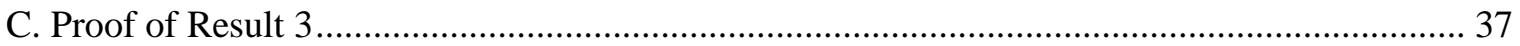

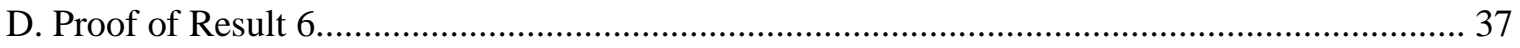

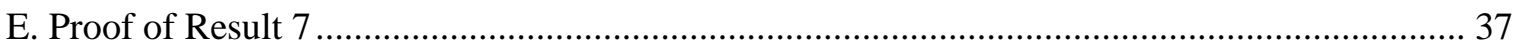

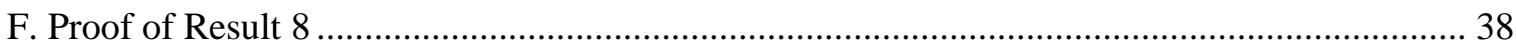

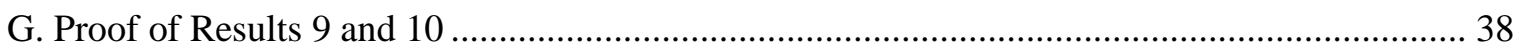

Figures

Figure 1. Growth of environmental quality in absence of exploitation .......................................... 9

Figure 2. Growth of environmental quality in presence of exploitation and sustainable exploitations. 10

Figure 3. Marginal benefit and marginal cost of the productive environment ...................................... 11

Figure 4. Welfare-maximizing sustainable environmental quality and exploitation............................ 15

Figure 5. Welfare-maximizing market-equilibrium sustainable exploitation and industry profits ....... 16

Figure 6. Competitive-equilibrium sustainable exploitation and environmental quality ...................... 17

Figure 7. Competitive-equilibrium sustainable exploitation and industry profits ................................ 18 
Figure 8 . Welfare-maximizing tax, tax revenues and industry profits 20

Figure 9. Welfare-maximizing quantity restrictions (exploitation vs. environmental quality) ............. 21

Figure 10. Monopoly sustainable exploitation and environmental quality ......................................... 23

Figure 11. Monopoly equilibrium and monopoly rent ..................................................................... 25

Figure 12. Sustainable biased-optimum exploitation and environmental quality ............................ 26

Figure 13. Welfare-maximizing exploitation (optimal converging trajectories) ................................... 30

Figure 14. Competitive exploitation (optimal converging trajectories) ............................................... 32 


\title{
The Sustainable Management of a Productive Natural Capital
}

\author{
Julien Xavier Daubanes ${ }^{1}$
}

\subsection{Introduction}

Economic development puts an increasing pressure on the environment. In industries which rely on the environment, the resulting environmental deterioration comes at the expense of the industry itself.

This phenomenon is especially manifest in the tourism industry. In Iceland, for example, where tourism is particularly motivated by the spectacle of wildlife, this sector significantly contributes to the national GDP. In the past few years, however, the extraordinary number of tourists' arrivals has probably already impacted the beautiful natural endowment of the country. Accordingly, Iceland's Minister of Tourism, Industry and Innovation Thordís Kolbrún R. Gylfadóttir mentioned in a recent interview ${ }^{2}$ the risk of "losing what makes [some areas] special-unique pearls of nature that are a part of [Icelanders'] image and of what [they are] selling." Welcoming a large number of tourists requires the building of infrastructure which obviously deteriorates the virginity of the environment in a direct manner. Moreover, even the least invasive form of tourism disturbs wildlife. For example, Granquist and Sigurjonsdottir (2014) recently showed that land-based seal watching affects the distribution and behaviour of harbour seals. These changes threaten the essence of Iceland's tourism business, which "needs to ensure that tourists that come [to Iceland] get a positive experience during their stay." As the minister put it, in the face of the boom of tourism in Iceland, "the sector and all [Icelanders] have to be careful not to become victims of [their] own success."

This paper is about those situations in which economic activity uses a natural resource capital on which it also relies. In such situations, a conflict arises between the short- and long-term interests of the industry. For example, in the case of nature-based tourism, on the one hand, it is tempting to welcome more tourists to increase current revenues,

1 This paper has been prepared for the seminar on "The Key to Sustainable Destination Development in Iceland," co-organized by the Icelandic Ministry of Finance and Economic Affairs, the Icelandic Ministry of Tourism, Industry and Innovation, and the Organization for Economic Cooperation and Development (OECD), at the occasion of the launch of the OECD's (2017) Economic Survey of Iceland on June 27, 2017 in Reykjavík. The current version of the paper has benefited from comments by participants at the seminar, as well as by Frank Jensen, Patrick Lenain and Douglas Sutherland. All errors are my own. Financial support from the OECD is gratefully acknowledged.

2 Available at https://www.bloomberg.com/news/articles/2017-03-16/victim-of-its-own-successiceland-considers-new-tax-on-tourists. 
whereas, on the other hand, more tourists deteriorate the future conditions under which the industry will operate, making future tourists' experience less valuable. Those situations call for a sustainable management that optimally balances the benefits of exploiting the natural environment and the benefits of maintaining its quality. In the words of The Economist (August 13, 2016), "Tourists could kill tourism," thus justifying the recent tendency of restricting this activity. Indeed, it cannot be hoped that economic competition will lead to an optimal sustainable management. Like in fisheries, the longrun costs of current exploitation are mostly incurred by others and, therefore, not fully taken into account by competitive operators.

The analysis of this paper will be highly stylized, both for simplicity and for the sake of generality. In the spirit of Zilberman (2014), the exploited natural capital will be treated like a renewable natural resource, so as to study its sustainable management in the face of ecological constraints. For concreteness, the example of tourism will be used throughout. Nevertheless, the analysis is also relevant to other sectors: obviously, the exploitation of renewable resources when the maintained quantity of resource facilitates its exploitation (e.g., fisheries); also, all situations in which the industry has caused so harmful levels of local pollution that it becomes less attractive to workers and investors (e.g., large industrial basins in rapidly-developing countries).

I will examine an industry with a single representative firm - e.g., environment-based tourism industry - exploiting a single productive natural capital - e.g., environmental quality in a given site - to supply a homogeneous good or service to consumers - e.g., tourists' experience. The extension to more-than-one capitals is straightforward. The renewable natural capital under study is assumed to have a limited capacity to recover from its exploitation. The fact that it is productive means that its level contributes to increase the value for consumers of the good or service that the industry produces.

The large literature originating in Schaefer's (1954) famous paper on the economics of renewable natural resources is directly relevant to our problem; see, among many others, Regev et al. (1998), Jensen et al. (2014), and Costello et al. (2016). The first part of the paper is consistent with the standard analysis of renewable resource economics: the welfare-maximizing sustainable exploitation, the competitive equilibrium, and sociallyoptimum public policies.

This paper is also complementary to the literature on the economics of nature-based tourism. The most famous contribution in this field is due to Lindberg (1991) who described the basic economic principles of the sector. In the same vein, Clarke (1993) explained that in presence of residents' property rights over natural sites, public intervention is not needed. However, these papers ignored the dynamic dimension of tourism, i.e. the impact of current tourism of the future environment. This dimension has been brought to the tourism literature recently by Arnason (2017). In this context, Arnason examined the optimal pricing of natural sites.

The analysis of this paper extends the existing resource economics literature as well as Arnason (2017) to cases in which the regulator has a particular interest for the industry's surplus. We examine three basic cases. First, the regulator may let the industry exert its market power so as to protect the natural capital: Indeed, as the famous adage goes, "the monopolist is the conservationist's best friend." Second, the regulator that monitors the industry may give more importance to the latter than it does to consumers because 
consumers are mostly residents of other jurisdictions. This is particularly relevant in the tourism sector as, like in Iceland, most tourists are foreigners and, in other sectors, when most of the output is exported. Therefore, in the spirit of, for example, Baron and Myerson (1982) and Hiriart and Martimort (2012), I examine the consequences of proindustry regulation. Third, industries that exploit a limited natural input generate an economic rent that is often an attractive target for governments with revenue needs. Resource-based sectors often received a special tax treatment and contribute to public finance in an extraordinary way. In Iceland's tourism sector, for example, the temptation to implement access fees is probably justified not only by the willingness to restrict tourism, but also by the potential tax revenues involved. Ministry officials said that the already-implemented hotel tax alone would bring not less than ISK 1.2 billion this year. The paper is organized as follows. Section II describes the productive natural capital and its exploitation. In Sections III and IV, the analysis is restricted to long-term sustainable exploitations. Section III is standard: It characterizes the welfare-maximizing exploitation, the competitive laisser-faire exploitation and discusses the optimal policies that allow to correct the latter. Section IV presents new results: the consequences of proindustry regulation and the sector's optimal taxation in presence of public revenue needs. Section $\mathrm{V}$ allows the system to converge to the long-term exploitation along a transition path; it verifies that the basic equilibria examined in the main parts are stable and discusses the implication of social and firms' discounting, both in the welfare-maximizing path and under competition.

\subsection{The Model}

There is a continuum set of dates $t \geq 0$. As will be clear shortly below, the analysis of Sections 1.2 to 1.4 will focus on time-invariant exploitation. Therefore, for notational simplicity, we omit time indexes as long as they are irrelevant, i.e., until Section 5.

\subsubsection{The Natural Capital}

There is a single natural site, whose environmental quality is modelled as a stock of capital and is denoted by $N \geq 0$. For example, $N$ can be thought of as the number of harbour seals in a particular site. More generally, it may measure the degree of wilderness of the site. This stock is naturally renewed at the rate

$$
\dot{N}=g(N),
$$

per unit of time. A dot on top of a variable means that the variable is differentiated with respect to time. The law of motion (1) is unidimensional and, therefore, neglects many factors determining the evolution of environmental quality, including its structure, its age and interaction with other environments. This simplifying representation supposes that other factors compensate each other in the long run, allowing the analysis to focus on the central aspect: how changes in the state of a natural site affect its future state. For example, in absence of any seal-watching tourism, the number of new seals in a particular site is a function of the population already present in the site.

The function $g$ is assumed differentiable, strictly concave and single peaked; there exists a level $N_{C C}$ such that $\mathrm{g}(N)<0$ if and only if $N>N_{C C}$. Furthermore, the natural capital is assumed unable to renew if it is destroyed: $g(0)=0$. In absence of economic exploitation, 
the natural capital $N$ grows at a positive rate $g(N)>0$ for any $0<N<N_{C C}$ and decreases at rate $g(N)<0$ beyond, for any $N>N_{C C}$. As a result, the level of natural capital naturally stabilizes at the carrying capacity level $N_{C C}>0$ such that $g\left(N_{C C}\right)=0$. This is depicted in Figure 1. For example, when few seals exist to reproduce in a given site, their population increases slowly but less so as there are more seals. When their population becomes higher, seals compete for limited food and become more vulnerable to predators. This natural evolution leads to a natural long-run equilibrium population of seals called the carrying capacity of the site. More generally, the natural dynamics of any environmental system can be considered to obey a similar average pattern.

Figure 1. Growth of environmental quality in absence of exploitation

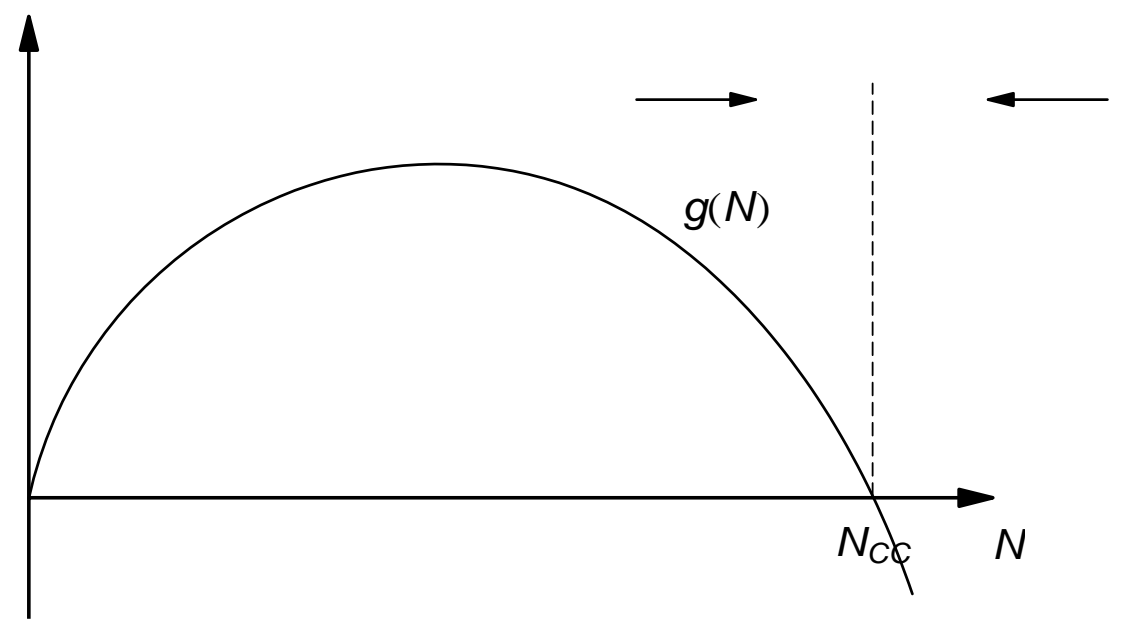

\subsubsection{Sustainable Exploitation}

There is a representative firm in a sector which exploits the natural capital at a rate $x \geq 0$. For example, $x$ is the number of tourists watching seals and this is causing seals to leave the site accordingly. More generally, that means that the environmental quality of a natural site has a limited absorption: It is negatively affected by the sector's exploitation, and needs time to recover from it according to its natural dynamics. For simplicity, let the exploitation rate and environmental quality be normalized in such a way the former deteriorates the latter on a one-for-one basis: The law of motion of the natural capital in presence of exploitation is given by

$$
\dot{N}=g(N)-x
$$

In such a context, for any level of natural capital $N$, it is reduced over time whenever exploitation $x$ exceeds the growth rate $g(N)$, and, vice versa, it is growing otherwise. This is depicted in Figure 2. 
Exploitation $\mathrm{x}>0$ is clearly incompatible with the long-run natural situation in which environmental quality remains at the carrying capacity level $N_{C C}$. At the same time, the above context gives rise to the possibility that exploitation be sustainable, in the sense that it does not further deteriorate the natural capital over time. Indeed, for a given environmental quality $0<N<N_{C C}$, an intensity of exploitation $x=g(N)>0$ leaves $N$ unchanged: By (2), $\dot{N}=0$ in such cases.

It follows that each point of the $g$ curve in Figure 2 depicts a particular sustainable exploitation, which is formally a couple $(N, x)$ where $x=g(N)$, so that $N$ remains in a steady state over time. For example, a well-chosen and constant positive number of tourists watching seals is compatible with a sustainable population of harbour seals, yet this population will be lower than the natural population $N_{C C}$. One remarkable sustainable exploitation maintains the natural capital at level $N_{\boldsymbol{M S E}}$, which maximizes the sustainable exploitation level $x_{M S E}$. For example, this corresponds to the highest possible number of tourists watching seals that does not induce the number of harbour seals to diminish over time; more tourists is in no way compatible with a maintained population of seals.

Figure 2. Growth of environmental quality in presence of exploitation and sustainable exploitations

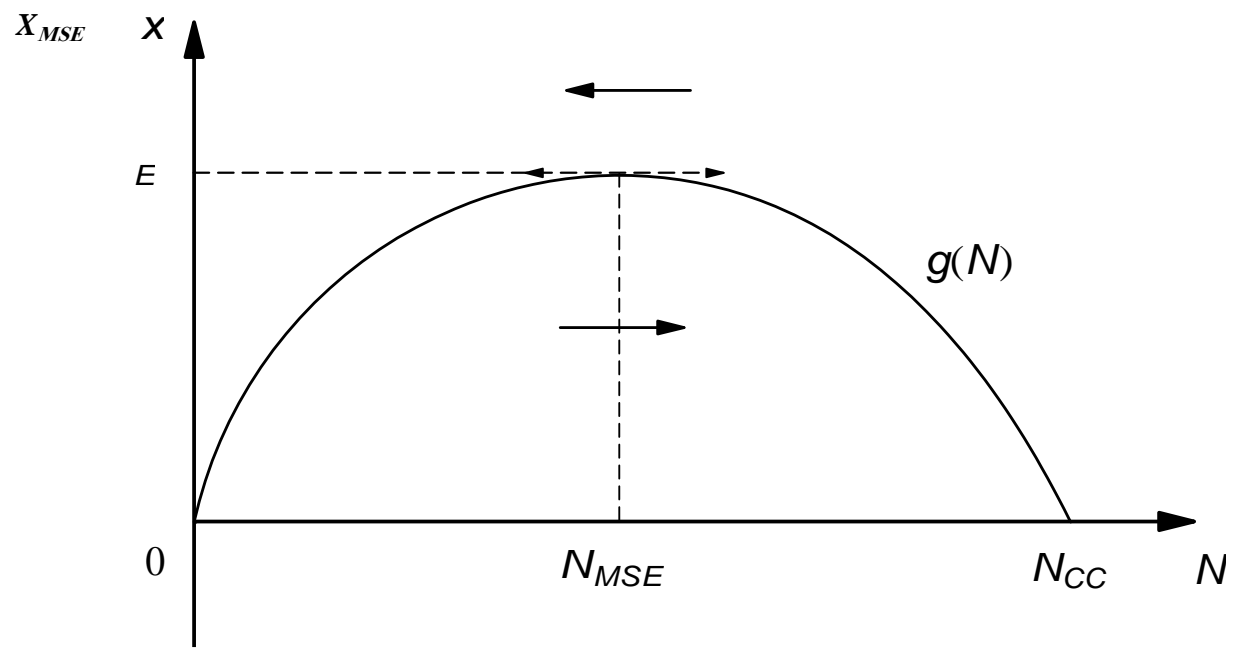

This "maximum sustainable exploitation" seems appealing. This intuition, however, will prove to be wrong, as it ignores the fact that, in general, the level of the natural capital affects the industry's business.

\subsubsection{Productivity}

Consider now that the natural capital is productive in the sense that its exploitation $x$ by the firm generates some services to its consumers who value the site's environmental quality $N$. Formally, there is a continuum of consumers whose aggregate utility is

$$
\boldsymbol{U}(\boldsymbol{x}, \boldsymbol{U}),
$$

which is expressed in some monetary units. Function $U$ is assumed twice differentiable and increasing not only with $x$ but also with $N$. It is further assumed to be jointly concave 
in its two arguments. As far as the exploitation rate $x$ is concerned, that means that consumers' marginal utility

$$
\frac{\partial U}{\partial x}
$$

is decreasing in $x$. For example, the most motivated tourists are willing to pay more for watching seals and, as exploitation increases, additional tourists are ready to pay less. Marginal utility (4) and, therefore, utility (3), are assumed to be increasing with environmental quality, with

$$
\frac{\partial^{2} U}{\partial x \partial N} \equiv \alpha>0
$$

This is a simplifying assumption meaning that, for example, although tourists differ in their willingness to pay to watch seals, their willingness to pay is increased when the population of seals becomes higher, in the same way for all tourists. Figure 3 depicts examples of marginal utility curves - reflecting the value of the marginal unit of exploitation - for two different levels of environmental quality $\underline{N}$ and $\bar{N}>\underline{N}$.

Figure 3. Marginal benefit and marginal cost of the productive environment

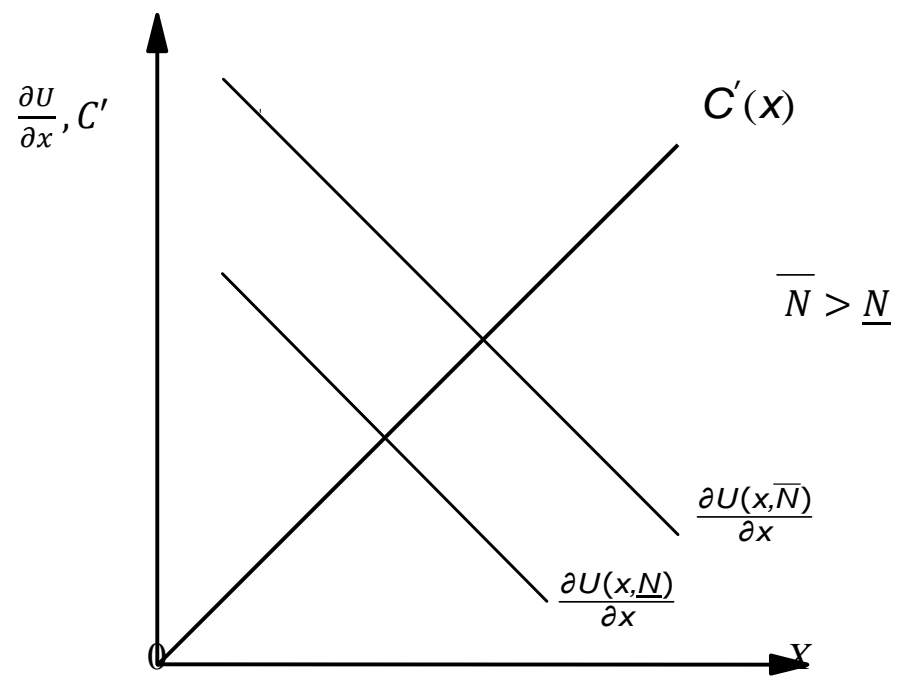

Furthermore, consider that the natural capital is essential to the firm's exploitation: Exploitation is uneconomic when $N=0$, as when the site's environmental quality is destroyed - e.g., there is no harbour seal to be watched by tourists. That means $U(x, 0)=$ 0 for any $x$ and, therefore,

$$
\frac{\partial U(x, 0)}{\partial x}=0
$$


Figure 3 also depicts the firm's marginal cost of exploiting the site, which is twice differentiable and convex. This reflects that, for example, welcoming more tourists requires the building of additional infrastructure e.g., hotels - that is marginally more costly; pieces of infrastructure are first built in the most central and least costly locations, and, then, in more remote locations which benefit less from agglomeration effects.

\subsection{Long-Term Steady-State Analysis}

In this section and Section IV, the analysis will focus on the steady states characterized above. That means that attention will be restricted to couples $(x, N)$ such that $x=g(N)$,

which are sustained over time. Indeed, such exploitations exhibit the intuitively desirable property that the industry's exploitation of the natural capital is sustainable; both the stock $N$ and the exploitation level $x$ remain constant from date 0 on.

This focus is a simplifying restriction: Since both variables $N$ and $x$ are the same across time, the steady-state analysis is the same irrespective of time. Therefore, under this restriction, the analysis is static rather than dynamic despite the dynamic relationship between exploitation and the level of natural capital. In a dynamic analysis, discounting plays a central role, i.e., the relative importance for the agents involved of present benefits and costs relative to benefits and costs at more distant dates, whereas in a steadystate analysis, discounting turns out to be irrelevant.

Section 1.5 will do away with the steady-state restriction: It will show how, in general, the economic system converges in the long run towards a stable steady-state situation in which variables are constant over time, thus justifying the steady-state analysis as a relevant approach for examining the exploitation of environmental quality in the very long run. In this less restrictive setting, Section 1.5 will allow to examine the role of discounting.

\subsubsection{Welfare-Maximizing Exploitation}

Consider first the problem of finding the sustainable exploitation which maximizes social welfare, i.e., the social net benefits: the net surplus generated by the sector to the industry and its consumers. Later in this section, we will examine the outcome of competitive competition within the industry.

\section{Social-Planner Optimum}

For simplicity, assume that there is a benevolent social planner able to dictate the exploitation $\boldsymbol{x}$ to the industry. The planner seeks to maximize the net long-run social benefits. Since both the net social benefit, the exploitation level and environmental quality are the same at each date, its problem is the same at each date:

$$
\max _{x, N} B(x, N),
$$

where

$$
B(x, N) \equiv U(x, N)-C(x)
$$


denotes the net social benefits. The planner chooses simultaneously $x$ and $N$, in such a way as to satisfy the sustainability constraint

$$
\mathrm{x}=\mathrm{g}(\mathrm{N})
$$

The constraint is introduced to allow the analysis to focus on sustainable exploitations. In other words, it ensures that the planner takes into account the relationship between the sustainable exploitation and the associated sustained environmental quality. Therefore, it implies that the planner integrates long-term consequences on the environmental quality of short-term exploitation.

The necessary conditions for the maximization of (7) under (8) are

$$
\frac{\partial B}{\partial x}=\lambda^{\circ}
$$

and

$$
\frac{\partial B}{\partial N}+\lambda^{\circ} g^{\prime}=0
$$

where $\lambda^{o} \geq 0$ is the social marginal cost of exploiting the natural capital, which reflects the long-term opportunity cost of the industry's exploitation for the industry and consumers altogether.

Condition (9) means that the net marginal benefit of exploitation should be equalized to the marginal opportunity cost of exploiting environmental quality. Condition (10) means that the marginal benefit of better environmental quality must be zero once its effect on the natural capital's growth is integrated.

As a result, the socially-optimum sustainable exploitation must satisfy

$$
\frac{\partial B}{\partial N}+\frac{\partial B}{\partial x} g^{\prime}=0
$$

To rule out uninteresting possibilities in which the sustainability constraint does not play any role, we focus on situations in which ${ }^{3}$

$$
\lambda^{\mathrm{o}}>0
$$

In this context, it follows from (9) that the welfare-maximizing exploitation must be such that $g^{\prime}<0$ and, therefore, is more conservative that the sustainable exploitation that maximizes exploitation:

$$
N^{\circ}>N_{M S E}
$$

\footnotetext{
${ }^{3}$ That means that, by assumption, the unconstrained maximization of $B(x, N)$ leads to violating the sustainability constraint, i.e., the solution $(x, N)$ in that case is such that $x>g(N)$.
} 
Appendix A shows that (11) characterises a relationship between environmental quality and the optimum exploitation

$$
x=o(N)
$$

which crosses the growth curve (8) only once, at the level $N^{\boldsymbol{o}}$, as depicted in Figure 4 . The welfare-maximizing sustainable exploitation is denoted by $\left(N^{\boldsymbol{o}}, x^{\boldsymbol{o}}\right)$.

Result 1 (Welfare-maximizing sustainable exploitation) In the sustainable exploitation that maximizes social welfare,

1. Exploitation $x^{o}$ is lower than the maximum sustainable exploitation $x_{M S E}$;

2. It induces more conservation of the natural capital: $N^{o}>N_{M S E}$. 
Figure 4. Welfare-maximizing sustainable environmental quality and exploitation

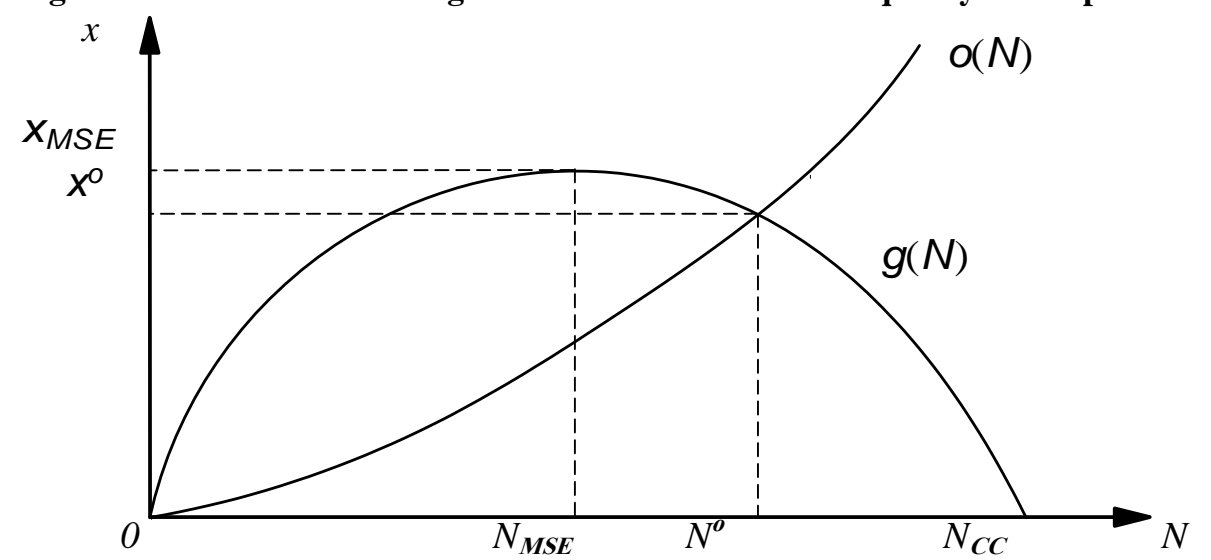

Result 1 contradicts the intuition that it would be optimum to implement the maxi- mum exploitation which is sustainable $\mathrm{x}_{\mathrm{MSE}}$ : Indeed, the latter ignores the fact that the consumer surplus increases with environmental quality. Once this is taken into account, it turns out that it is socially beneficial to be more conservative, despite the fact that this means a lower exploitation.

\section{Welfare-Maximizing Market Equilibrium}

In reality, there is no social planner dictating the industry the extent to which it should exploit the natural capital. Nevertheless, if the industry consisted of a single competitive operator, fully responsible for the long-run evolution of the natural capital, it would induce a market equilibrium that would maximize social welfare.

In that case, assuming again a steady-state exploitation, the market for the good or service produced by the natural capital's exploitation would establish a price

$$
p=\frac{\partial U}{\partial x}
$$

equal to the marginal consumer utility, constant over time. The industry would seek to maximize its profit at each date

$$
\max _{x, N} p x-C(x)
$$

subject to the sustainability constraint (8), thus integrating the impact of exploitation on the long-run sustained level of natural capital. It would also integrate that the price $\mathrm{p}$ increases with the environmental quality as per $d p / d N=\alpha$. However, as competitive, the operator would ignore the possibility of manipulating the price by restricting exploitation, taking the price in (13) as independent of $x$. However, Appendix B shows that the firstorder condition for the maximization of (14) under (8), with the market equilibrium condition (13), characterizes the welfare-maximizing sustainable exploitation $\left(N^{o}, x^{o}\right)$. It further identifies a gap between the price $p^{\circ}=\frac{\partial U\left(x^{\circ}, N^{\circ}\right)}{\partial x}=C^{\prime}\left(x^{\circ}\right)+\lambda^{\circ}$ and the marginal cost, which results in an economic rent 


$$
\lambda^{0} \mathrm{x}^{0}>0
$$

that accrues to the industry on top of ordinary profits. This rent is represented in Figure 5 by the diagonally hatched area. Total profits, including this rent, correspond to the vertically hatched area.

Result 2 (Welfare-maximizing market-equilibrium sustainable exploitation) If there was a single competitive firm in the industry, the market-equilibrium sustainable exploitation would be the one maximizing social welfare. In that case, the price would exceed the marginal exploitation cost, generating a rent accruing to the industry.

In ordinary sectors which do not rely on a natural capital, the competitive equilibrium exhibits the standard equality between price and marginal cost. In the industry under study, by contrast, the marginal rent $\lambda_{0}>0$ emerges because there is an opportunity cost of exploiting the natural capital: More exploitation deteriorates the productive natural capital in the long run, which undermines the exploitation itself in the long run. As a result, it is socially desirable that exploitation be limited below the level that would be optimal in ordinary sectors. For example, that means that the number of tourists should be limited to some level despite the fact that some tourists would be ready to cover the cost of their experience. The socially optimal number of tourists is such that the marginal tourist is ready to pay not only for the cost of his or her experience, but also for the opportunity cost due to his or her long-term impact on the natural capital and, therefore, the long-run consequences for the entire sector.

Figure 5. Welfare-maximizing market-equilibrium sustainable exploitation and industry profits

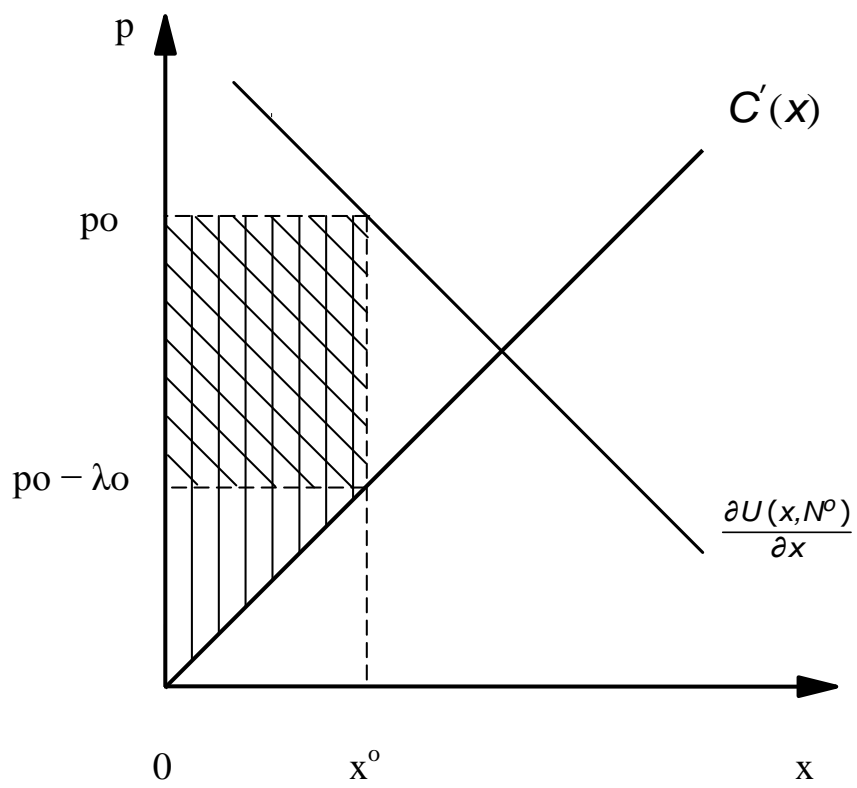

\subsubsection{Competitive Equilibrium without Public Policy}

As a matter of fact, modern economies are mostly market economies which do not rely on centralized planning. Moreover, industries often consist of many operators. 
For simplicity, consider now that there is a continuum of competitive firms in the industry and that no regulation is implemented. As far as profit is concerned, the industry maximizes the aggregate profit taking the market equilibrium price (13) as given:

$$
\max _{x} p x-C(x)
$$

However, unlike the sole owner of the previous subsection, the industry's firms do not take into account the impact of their individual exploitation on the long-run level of their common natural capital; indeed, the impact of small firms is virtually fully borne by the rest of the industry. As a result, (15) leads to the standard price-marginal-cost equality $\boldsymbol{p}$ $=\boldsymbol{C}^{\prime}(\boldsymbol{x})$, where (13) implies that net social benefits of exploitation are maximized as if exploitation had no long-run opportunity cost in terms of the sustained natural capital; in equilibrium,

$$
\frac{\partial B}{\partial x}=0
$$

rather than $\partial \mathrm{B} / \partial \mathrm{x}>0$ as per (9).

According to (16), the profit-maximizing exploitation depends on the level of the natural capital. Appendix $\mathrm{C}$ shows that the relationship between the latter and the former is given by an increasing function

$$
x=e(N),
$$

as depicted in Figure 6. Indeed, Appendix $\mathrm{C}$ shows that, for any given environmental quality $N$,

$$
\mathrm{e}(N)>o(N)
$$

The competitive-equilibrium exploitation is sustainable when it intersects the growth curve (8). It follows from (18) that the competitive-equilibrium sustainable exploitation $\left(N^{e}, x^{e}\right)$ is only compatible with a lower level of natural capital.

Figure 6. Competitive-equilibrium sustainable exploitation and environmental quality

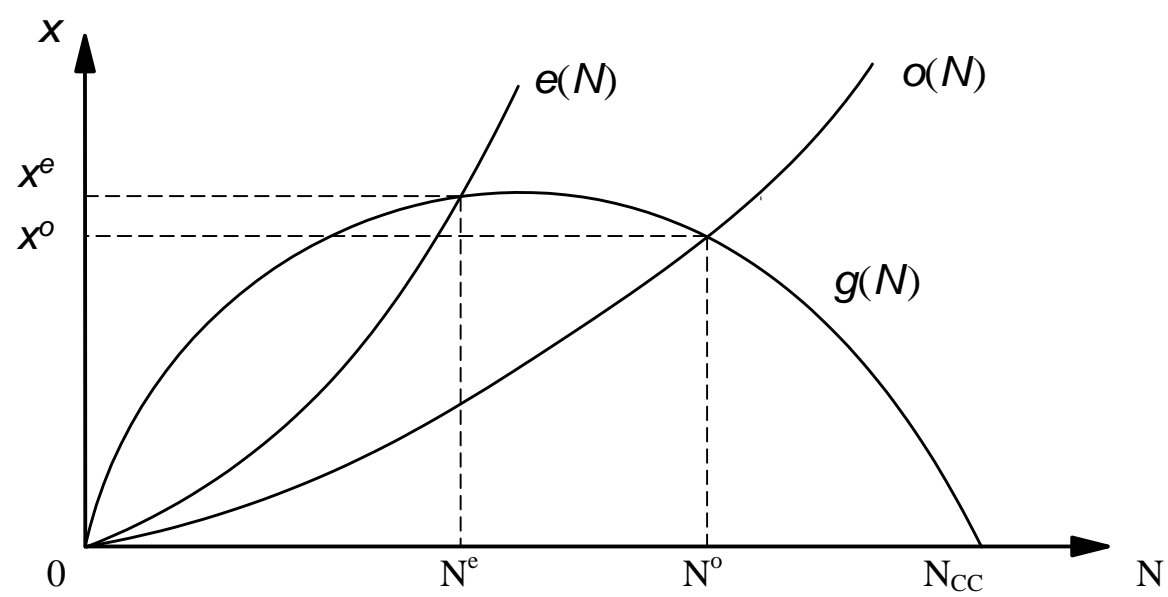


Result 3 (Competitive-equilibrium sustainable exploitation). In the competitiveequilibrium sustainable exploitation,

1. The natural capital is less conserved than when welfare is maximized: $\boldsymbol{N}^{e}<\boldsymbol{N}^{\boldsymbol{o}}$;

2. Exploitation $\underline{x}^{e}$ may be higher than $\boldsymbol{x}^{\boldsymbol{o}}$ or, in catastrophic cases, lower.

Indeed, environmental quality may be deteriorated by a competitive sector to such an extent that it is only compatible with a lower exploitation in the long run.

By definition, the welfare-maximizing exploitation generates a higher level of social welfare to consumers and firms altogether so that the competitive-equilibrium is socially inefficient. What are the specific implications of the competitive-equilibrium exploitation for the industry's profit? On the one hand, for any level of exploitation, the equilibrium price (13) is lower since consumers are ready to pay less for less conservation. On the other hand, the equality between the price and the marginal cost implies that there is no rent accruing to the industry. The total profit of the sector is represented in Figure 7 by the hatched area.

Result 4 (Competitive-equilibrium sustainable exploitation and industry profits). In the competitive-equilibrium sustainable exploitation,

1. Consumers' marginal utility $\partial U\left(x, N^{e}\right) / \partial x$ is lower than $\partial U\left(x, N^{o}\right) / \partial x$ when social welfare is maximized;

2. There is no exploitation rent accruing to the industry.

In catastrophic cases in which exploitation is lower than when social welfare is maximized, the industry's profit is lower than if it was taking into account the opportunity cost of exploitation.

Figure 7. Competitive-equilibrium sustainable exploitation and industry profits

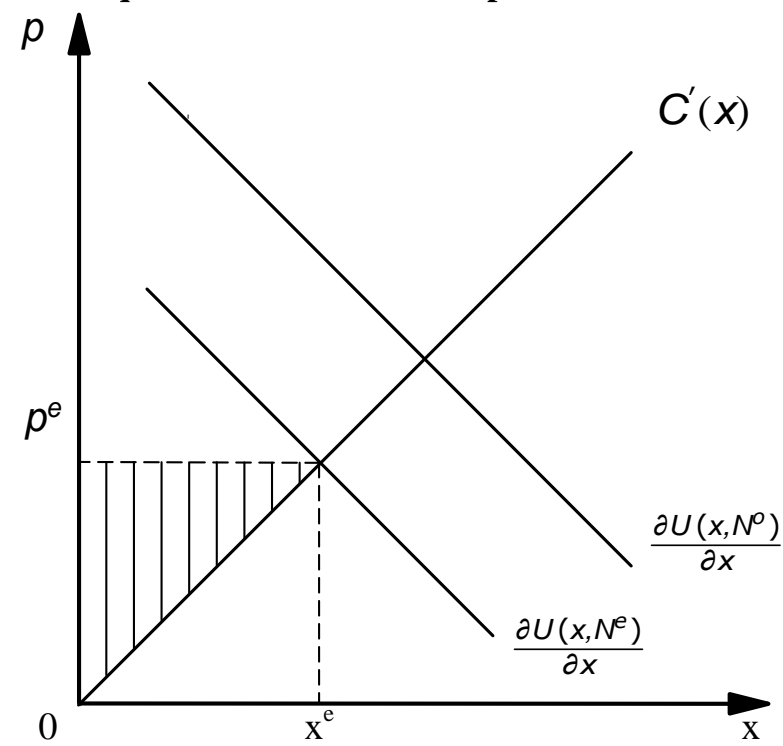

With a standard externality caused by the industry, the industry's activity is excessive, which comes at the expense of the rest of society, but at the benefit of the industry. With 
a productive natural capital, by contrast, the fact that the industry does not take into account its impact on the long-run sustained level of environmental quality jeopardizes its profit.

\subsubsection{Optimal Policy: Tax vs. Restrictions}

The previous subsection calls for public intervention to restore the efficiency of the sector. Assume now that a regulator monitors the industry. The most basic way correct the inefficient market outcome is to penalize its exploitation with a tax. For example, the possibility of implementing a tourists' fee has been discussed - see, for example, Arnason (2017).

Assume an exploitation tax equal to the social user cost

$$
\tau^{0}=\lambda^{0}
$$

which is the value of $\lambda$ prevailing under the welfare-maximizing sustainable exploitation. This way, firms maximize, rather than (15),

$$
\max _{x} p x-\lambda x-C(x)
$$

where the market equilibrium price $p=\partial U / \partial x$ of (13) is taken as given. The above formulation, therefore, supposes that the tax falls on firms, which receive the net-of-tax price $p-\tau^{o}=\partial U / \partial x-\tau^{o}$. One can verify, however, that it is formally equivalent to the formulation in which the tax falls, instead, on consumers. In this case, consumers would pay the inclusive-of-tax price $p+\tau^{o}=\partial U / \partial x$, and firms would receive $p=\partial U / \partial x-\tau^{o}$. It follows that, unlike the popular belief, the distributional consequences of taxing exploitation are the same irrespective of whether the tax is imposed to firms or consumers. In either case, the introduction of the tax $\tau^{o}=\lambda^{o}$ puts the industry in the same situation as if they were taking into account the opportunity cost of their exploitation in terms of the long-run level of natural capital.

For simplicity, tax revenues $\tau^{o} x$ are assumed not to cause any distortion, as when they can be rebated in a lump sum way. Recalling the market equilibrium price (13), it can easily be verified that problem (19) reproduces the welfare-maximizing sustainable exploitation characterized by condition

$$
\frac{\partial B}{\partial x}=\lambda
$$

and the sustainable constraint (8).

However, this equilibrium differs from the welfare-maximizing equilibrium examined in Subsection 1.3.1 because a tax has distributional consequences. Indeed, the price accruing to firms in this case is $p^{o}-\tau^{o}=\partial U / \partial x-\tau^{o}$, rather than $p^{o}$. The rent earned by the industry in Subsection 1.3.1 is now fully captured by the regulator as tax revenues $\tau^{o} x^{o}$. In Figure 8 , these revenues are represented by the diagonally hatched area. The hatched area below this rectangle shows the actual profit of the industry. Nevertheless, the rent captured by the tax may be related to the industry in a lump sum manner so as to 
ensure that it earns the same total profit as in the welfare-maximizing competitive equilibrium of Subsection 1.3.1. In general, to sum up, the distributional consequences of the corrective tax examined here depend only on how the tax proceeds are rebated, but not at all on whether the tax is imposed to firms or consumers.

The other basic way of restoring efficiency is to restrict quantities. For example, tourists' restrictions have often been proposed to limit the long-run impact of tourism on environmental quality. In practice, such restrictions may be implemented via a system of tradable rights at the natural site level. However, Figure 8 indicates that an exploitation cap at the optimal level $x^{o}$ is not only compatible with the sustained welfare-maximizing environmental quality $N^{o}$, but also with the lower level $N$. In the latter case, the exploitation is at the optimal level $x^{o}$ but the low environmental quality $N$ implies that consumers are only ready to pay $\partial U\left(x^{o}, N\right) / \partial x<\partial U\left(x^{o}, N^{o}\right) / \partial x$, and that the industry profits are reduced unambiguously compared with the welfare-maximizing market equilibrium of Subsection 1.3.1. This sub-optimal equilibrium, however, can only realize if the exploitation cost is low enough so that it is covered by the market price, i.e., as when $\partial U\left(x^{o}, N\right) / \partial x \geq C^{\prime}\left(x^{o}\right)$. In general, that means that restricting exploitation does not guarantee that there will be enough conservation in the long run.

This possibility calls for an alternative policy to ensure a minimum level of environmental quality No, for example, by setting adequate norms on the natural site or by implementing protected areas within the site. In this case, the competitive market is induced to exploit the site at level $x^{o}$, and the same rent as in the welfare-maximizing equilibrium would accrue to the industry.

Figure 8. Welfare-maximizing tax, tax revenues and industry profits

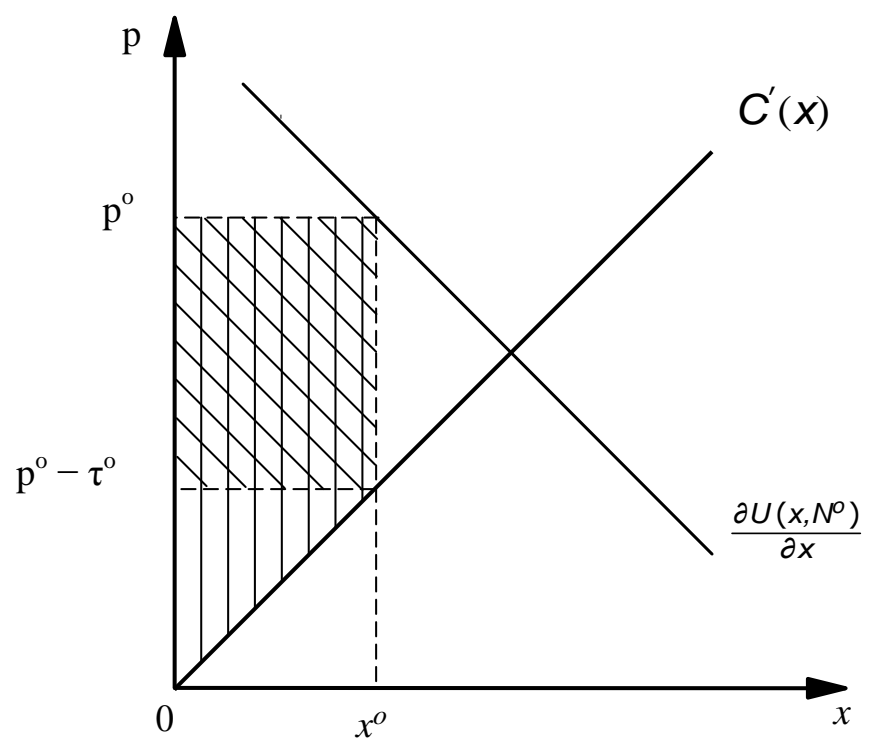

Result 5 (Welfare-maximizing policy: tax vs. restrictions) In general, there are three ways of implementing the welfare-maximizing sustainable exploitation:

1. An exploitation tax $\tau^{o}=\lambda^{o}$ equal to the social cost of exploitation; assuming that the tax proceeds can be rebated in a lump sum way, the distributional impact of the tax does only depend on this redistribution, irrespective of whether the tax is imposed on firms or consumers; 
2. An exploitation restriction at level $x^{0}$ does not guarantee that there is enough conservation of the natural capital; when there is insufficient conservation, the industry's profits are reduced;

3. A direct protection of the natural capital at level $N^{o}$.

Minimum measures to protect environmental quality may also be used as a complement to an exploitation restriction, so as to avoid the possibility that the latter turns out to be ineffective.

\subsection{Monopoly Power, Industry-Oriented Regulation, and Public Finance}

This section extends the management of productive natural capitals to cases in which the regulator gives more importance to the industry than it does to consumers. This may be justified in a variety of empirically-relevant situations. First, letting the industry exert its market power may induce more conservation. Second, consumers may be residents of other jurisdictions that the regulator does not represent. Third, the industry's rent may be an attractive source of public revenues for the government.

Figure 9. Welfare-maximizing quantity restrictions (exploitation vs. environmental quality)

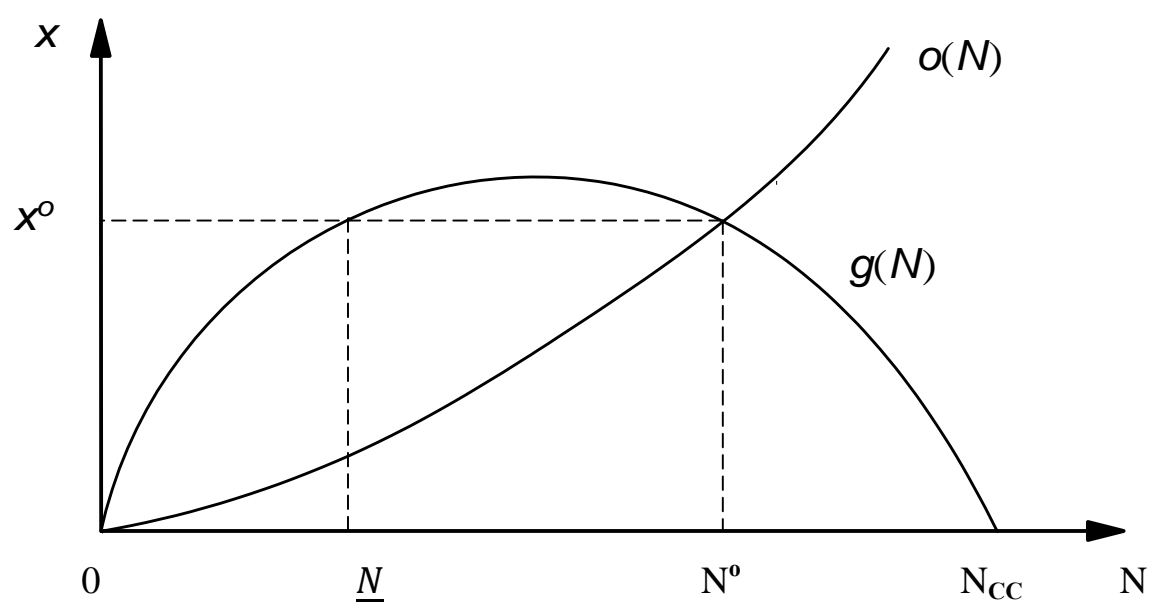

\subsubsection{Monopoly Power}

Natural sites are attached to specific locations. Moreover, they are often unique. The most beautiful spectacles of wildlife are hardly substitutable with other sites. For these reasons, operators exploiting natural capitals often have monopoly power. Following the adage that "the monopolist is the conservationist's best friend" in the face of supply limitations (e.g., Solow, 1974), it might be tempting to let a concentrated industry exert its influence over the market for the goods and services produced from environmental quality. For simplicity, assume that the industry is a monopoly. Although extreme, this case is sufficient to understand the distortion implied by the concentration of an industry exploiting a productive natural capital. 
It is textbook wisdom to consider that monopoly power tends to reduce the output. For example, one should expect a monopoly to welcome fewer tourists than an otherwise similar competitive sector. This subsection will show that this standard logic does not apply to the case of an industry that relies on a productive natural capital.

Unlike the competitive industry of Subsection 1.3.3, a monopoly takes into account that its exploitation affects the equilibrium market price (13). Its problem becomes, instead of (15),

$$
\max _{x} \frac{\partial U}{\partial x} x-C(x)
$$

To focus on the effect of monopoly power, consider that the monopoly, like the competitive sector, does not internalize the sustainability constraint (8): It is solely concerned about profit and does not take into account the long-run impact of its exploitation on the level of the natural capital.

The first-order condition for the maximization in (20) is the standard equality between marginal cost and marginal revenue, instead of price under competition:

$$
\frac{\partial U}{\partial x}-\frac{\partial^{2} U}{\partial x^{2}} x=C^{\prime}(x),
$$

where the second term on the left-hand side is negative to reflect that the marginal exploitation revenue of the monopolist is lower than the price $p=\partial U / \partial x$ as more exploitation contributes to depress the market price. Condition (21) can be written

$$
\frac{\partial B}{\partial x}=-\frac{\partial^{2} B}{\partial x^{2}} x,
$$

which is strictly positive, rather than zero under competition. Appendix D shows that the latter condition defines a relationship between environmental quality and the monopolist' profit-maximizing exploitation like

$$
x=m(N)
$$

Appendix D further shows that, for any given $\mathrm{N}$, the monopolist's exploitation $x=m(N)$ is strictly lower than the competitive-equilibrium exploitation $x=e(N)$. As depicted in Figure 10, it follows that the sustainable monopoly exploitation $\left(N^{m}, x^{m}\right)$, given by the intersection of the $\mathrm{m}$ and the $\mathrm{g}$ curves, exhibits more conservation than under competition, thus confirming the well-known adage.

Nevertheless, the standard logic that monopoly power tends to reduce the output does not apply here. On the one hand, the monopolist has a lower exploitation level for a given level of natural capital. On the other hand, it leads to a higher sustained level of natural capital in the long run, which contributes to increase its exploitation. The following result shows that the analysis of market power is not standard when the industry relies on a productive natural capital.

Result 6 (Monopoly exploitation) In the sustainable monopolistic exploitation, 
1. The monopoly conserves the natural capital more than an otherwise-similar competitive industry: $N^{m}>N^{e}$;

2. Exploitation $x^{m}$ may be lower than $x^{e}$ or, if competition induces a very low conservation $N^{e}<N_{\text {MSE }}$, higher;

3. The industry profits include a monopoly rent.

The latter rent is illustrated in Figure 11, where the intersection of marginal cost with marginal revenue determines the quantity in such a way that the price exceeds the marginal cost. The monopoly rent corresponds to the diagonally-hatched area.

Figure 10. Monopoly sustainable exploitation and environmental quality

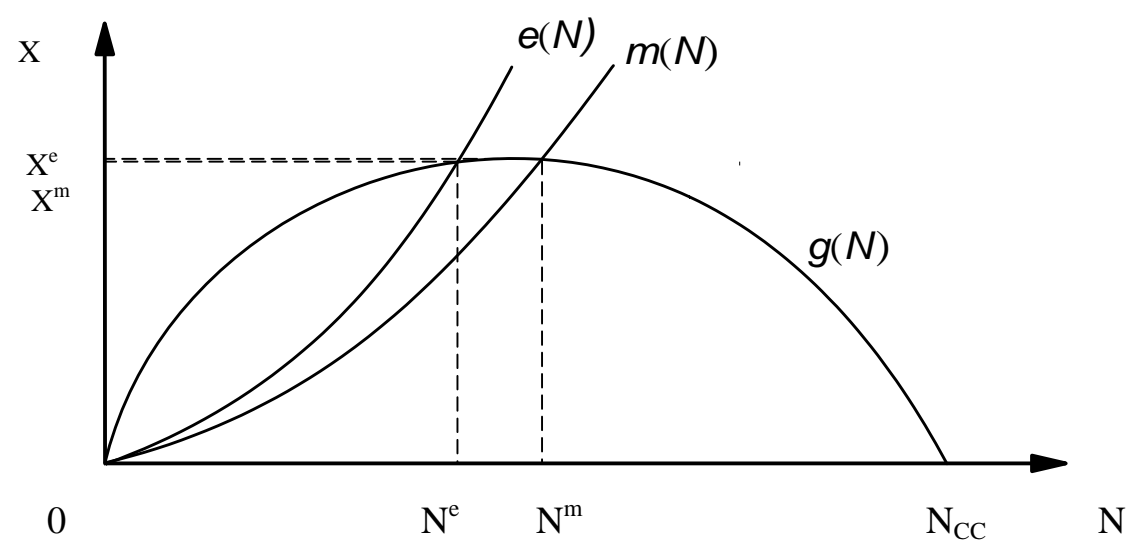

\subsubsection{Pro-Industry Regulation}

Consumers of the industry may not be residents of the regulator's jurisdiction. For example, the number of tourists in Iceland largely exceeds the number of Icelanders. In such cases, as when an industry's output is mostly exported, the regulator should not seek to maximize the total welfare generated by the industry. Instead, it should pursue an objective that gives more weight to the local industry.

This subsection examines the exploitation that a regulator should seek to implement in this context. For that, consider that there is a social planner that seeks to solve, instead of problem (7), the following one:

$$
\max _{x, N} B(x, N)+\beta \pi
$$

with

$$
\beta>0,
$$

subject to the sustainability constraint (8), where

$$
\pi=\frac{\partial U}{\partial x} x-C(x)
$$


That means that the pro-industry social planner takes into account that the sustainable exploitation determines the profit (25) that would accrue to the industry, in a way reminiscent of a monopoly.

Therefore, the problem of the planner in Subsection 1.3.1 is modified to add a monopoly dimension to the planner's problem. However, unlike the monopoly examined in the previous subsection, the planner, like in Subsection 1.3.1 takes into account the impact of exploitation on the long-run level of the natural capital. Accordingly, if $\beta$ was zero in (25), the planner's solution would be the welfare-maximizing sustainable exploitation. 
Figure 11. Monopoly equilibrium and monopoly rent

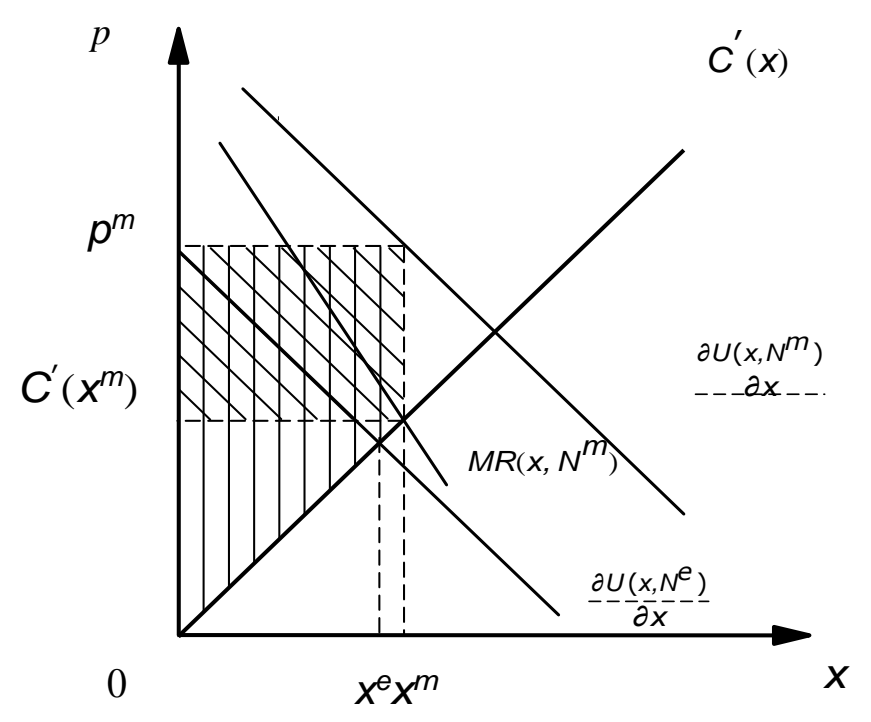

The standard intuition is that pro-industry regulators are too lax, allowing an excessive exploitation, which comes at the cost of an insufficient conservation of the natural environment. However, the previous subsection highlighted that the monopoly dimension of the regulator's objective does not obey the standard logic. This calls for a rigorous examination of the effect of the bias $\beta$.

Appendix E establishes the following condition for the maximization of (24):

$$
\frac{\partial B}{\partial N}+g^{\prime} \frac{\partial B}{\partial x}=-\frac{\beta}{1+\beta} g^{\prime} \frac{\partial^{2} U}{\partial x^{2}} x
$$

which is strictly negative as $\boldsymbol{\beta}>\boldsymbol{0}$, instead of zero when the planner maximizes welfare as per (26). Accordingly, Appendix E shows that the latter condition defines a relationship

$$
x=b(N),
$$

between the biased-optimum exploitation and environmental quality, where

$$
b(N)<o(N) .
$$

That means that, for any level of the natural capital, the pro-industry planner's exploitation is lower than the welfare-maximizing exploitation.

As Figure 12 illustrates, this implies that the sustainable biased-optimum exploitation commands both a lower sustainable exploitation level and more conservation in the long run. 
Figure 12. Sustainable biased-optimum exploitation and environmental quality

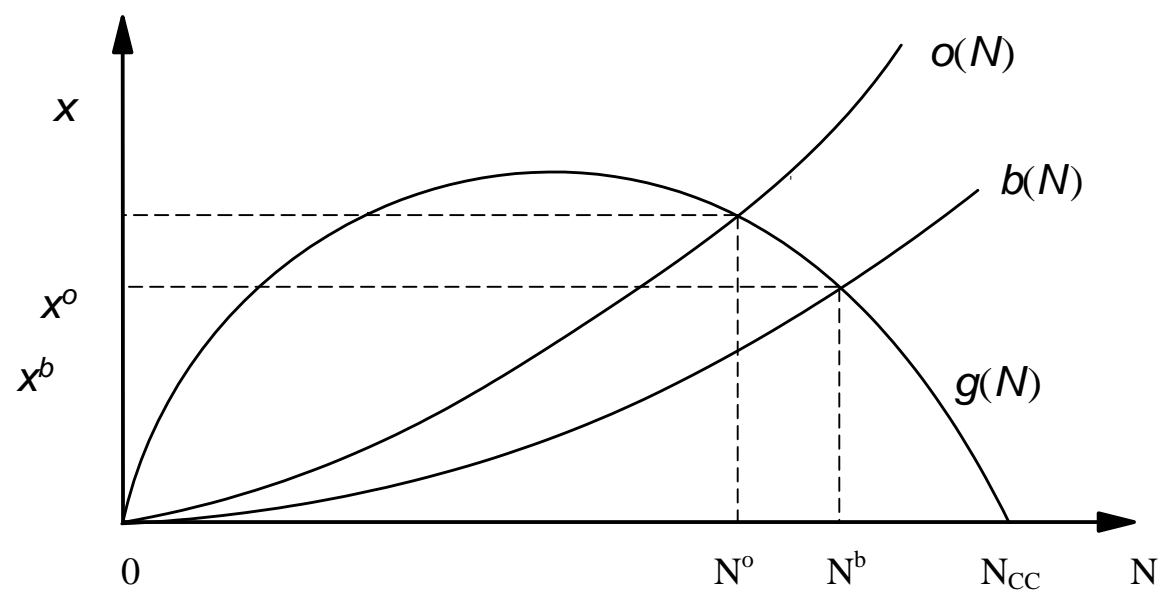

Result 7 (Pro-industry welfare-maximizing exploitation) In the sustainable exploitation that maximizes social welfare with a pro-industry bias,

4. Exploitation $x^{b}$ is lower than the welfare-maximizing sustainable exploitation $x^{o}$;

5. The natural capital is more conserved than when social welfare is maximized: $N^{b}$ $>N^{\circ}$.

A regulator that is more concerned about the profit of the industry that it supervises than it is about consumers' utility should implement more conservation of the productive natural capital and less exploitation of this capital.

\subsubsection{Government's Tax Revenue Needs}

More now than ever in the aftermath of the global financial crisis, many governments are struggling to meet their public revenue needs. In this context, industries relying on a productive natural capital appear to be very attractive targets for governmental taxation, due to the rent that their activity generates. Iceland, to extend the paper's recurrent example, makes no exception.

Tax collection has hitherto been assumed corrective, thus resolving a distortion rather than causing one. However, in presence of public revenue needs, tax collection becomes distortionary. Assume that raising one unit of public revenue costs $1+\delta$ units of social welfare; $\delta>0$ is called the marginal cost of public funds. In this case, units of tax revenues raised from the exploitation of the natural capital are valued by the government as $1+\delta$ units of the welfare objective.

To focus the analysis on the role of public revenue needs, assume that the industry is competitive and does not take into account its impact on the long-run level of natural capital, like in Subsection 3.2. Further assume that exploitation is taxed at a unit level $\tau$, that is to be determined by the regulator. Variables evaluated in the competitive equilibrium for a given tax will be denoted by a tilde on top of them. The tax $\tau$ generates a gap between the marginal utility of consumers and the competitive industry's marginal cost: 


$$
\frac{\partial U(\tilde{x}, \widetilde{N})}{\partial x}-\tau=C^{\prime}(\tilde{x})
$$

The regulator sets the tax in such a way as to maximize the total welfare generated by the sector, while taking into account $(l)$ the effects of its tax on equilibrium quantities, (ll) the contribution of tax revenues to the total welfare, and ( $(l l l)$ the sustainability constraint, i.e., the impact of its tax on the long-run level of the natural capital. Formally, its problem is

$$
\max _{\tau} U(\tilde{x}, \widetilde{N})-\tau \tilde{x}-C(\tilde{x})-(1+\delta) \tau \tilde{x}
$$

subject to the sustainability constraint (8), which takes the form $\check{x}=g(\widetilde{N})$.

If $\delta$ was zero, the situation of the regulator would be identical to that of Subsection III.C: The optimal tax would be set equal to $\lambda^{o}$ so as to implement the welfare-maximizing sustainable exploitation. In the sequel, for simplicity, we examine the case of a cost of public funds $\delta$ which is strictly positive and arbitrarily small; this is sufficient to understand the optimal distortion that the regulator should impose to the sector.

In Appendix F, the following condition is obtained for the maximization of (30):

$$
\frac{\partial B}{\partial N}+g^{\prime} \frac{\partial B}{\partial x}=-\delta g^{\prime}\left[\frac{\tilde{x}}{\frac{d \tilde{x}}{d \tau}}+\tau\right]
$$

which is negative, instead of zero when welfare is maximized in absence of public revenue needs, as per (11) with $\delta=0$. The above condition defines the following relationship between the exploitation level and the level of environmental quality:

$$
\tilde{x}=f(\widetilde{N})
$$

which is strictly lower than the function $\mathrm{o}(N)$ in (12) for a given capital level $N=\widetilde{N}$; a strictly positive cost of public funds commands to exploit less.

The same conclusion as in the previous subsection follows: The sustainable welfaremaximizing exploitation is lower in presence of public revenue needs, and induces a higher level of sustained natural capital.

Let us consider now the optimal tax level in this context. Appendix F shows that the optimal exploitation tax is

$$
\tau^{f}=-\frac{\delta}{1+\delta} \frac{1}{\tilde{\xi}}-\frac{\partial U}{\partial N} \frac{1}{g^{\prime}}
$$

where

$$
\xi \equiv-\frac{x}{d x / d \tau}=x\left(\frac{1}{\xi_{D}}+\frac{1}{\xi_{S}}\right)>0
$$


is the tax elasticity of the competitive equilibrium exploitation, in which the demand and supply elasticities correspond to the standard expressions $\xi_{D} \equiv-(\partial U / \partial x) /\left(x \partial^{2} U / \partial x^{2}\right)$ and $\xi_{S} \equiv C^{\prime} /\left(x C^{\prime \prime}\right)$.

Expression (33) looks complex but, in fact, brings up simple insights. The first tax component on the right-hand side of (33) is the standard Ramsey (1927) tax to be imposed on the output of an ordinary sector that does not rely on a productive natural capital. The second term on the right-hand side is the additional tax component that emerges when the sector's activity relies on a natural capital. It would vanish otherwise, as when consumers' utility was independent from environmental quality. Therefore, our formula extends Ramsey's taxation analysis to the sustainable management of productive natural capitals. This second term is positive, meaning that the exploitation of a natural capital commands to tax the sector's activity at a higher level. Furthermore, this additional tax component positively increases, other things being held constant, with the sensitivity of consumers' utility to environmental quality, as well as with the effect of the natural capital on its growth rate.

The following result summarizes the above findings.

Result 8 (Welfare-maximizing taxation with public revenue needs) In presence of public revenue needs,

1. The welfare maximizing tax $\tau^{f}$ on the exploitation of a productive natural capital is higher than the optimal tax on the output of an otherwise-similar ordinary sector;

2. This tax induces a lower exploitation and more conservation of the natural capital than in absence of public revenue needs.

\subsection{Short-Run Transitional Dynamics, Long-Term Stability, and Discounting}

The analysis of Sections 1.3 and 1.4 has focused on sustainable exploitations. For that, a sustainability constraint was introduced, restricting exploitation to be in a steady-state. This approach is relevant to examine long-run solutions that can be sustained over an arbitrarily long period of time.

However, in the short term, things are not so simple: Policy makers face a given level of natural capital, which only changes over time as a function of natural growth and exploitation, as per (2). Therefore, implementing a sustainable exploitation that satisfies constraint (8) takes time whenever the targeted level of natural capital differs from the current level.

In this section, we do away with the restriction that the industry's or regulator's problem is to pick up a sustainable exploitation. Instead, modifying the level of natural capital requires modifying the exploitation over a sufficiently long period of time. In this much more general and complex setting, it will turn out that a short-run transition phase converges towards a long-run steady state resembling the sustainable exploitations of sections 1.3 and 1.4. This assures the theoretical relevance of the previous steady-state analysis. The analysis will also allow examining the role of discounting.

For brevity, let us focus on two main cases: first, the social planner's problem of maximizing social welfare and, second, the competitive industry. The interested reader 
can verify that other cases - sole competitive operator, monopoly, pro-industry regulator, and public revenue needs - exhibit similar properties.

\subsubsection{Welfare-Maximizing Exploitation}

The absence of sustainability constraint means that exploitation changes over time: As a result, the social planner's problem differs from one date to the other. One cannot, in this case, single out a particular date as representative of all others, unlike the steady- state analysis. In the sequel, we make the time index - hitherto omitted for notational simplicity - explicit below all variables.

The intertemporal problem of the social planner is to maximize the discounted stream of net social benefits over the infinite time period $t \geq 0$ :

$$
\max _{\left(x_{t}\right)_{t \geq 0},\left(N_{t}\right)_{t \geq 0}} \int_{0}^{\infty} B\left(x_{t}, N_{t}\right) e^{-r t} d t
$$

where $r>0$ is an arbitrarily small social discount rate, subject to the law of motion

$$
N_{t}=g\left(N_{t}\right)-x_{t}
$$

Appendix G shows, by applying the Maximum Principle, that the solution to the intertemporal maximization of (34) under (35) obeys a two-dimensional dynamic system.

At each date $t \geq 0,\left(x_{t} N_{t}\right)$ should evolve according to two equations. The first one is simply (35), which gives the law of motion of $N_{t}$. It predicts that $N_{t}$ remains unchanged over time according to whether $x_{t}$ is higher or lower of the $\dot{N}_{t}=0$-isocline:

$$
x_{t}=g\left(N_{t}\right)
$$

which is depicted in Figure 13 by the $\mathrm{g}$ curve.

The second equation yields the optimal dynamics of exploitation $x t$ :

$$
\dot{x}_{t}=\frac{1}{\frac{\partial^{2} B}{\partial x^{2}}}\left[\alpha\left(x_{t}-g\left(N_{t}\right)\right)+r \frac{\partial B}{\partial x}-\frac{\partial B}{\partial N}-g^{\prime} \frac{\partial B}{\partial X}\right]
$$

It predicts that $x_{t}$ increases or decreases depending on whether it is higher or lower than the following $\dot{\dot{x}_{t}}=0$ isocline:

$$
x_{t}=g\left(N_{t}\right)+\frac{1}{\alpha}\left(\frac{\partial B}{\partial N}+\frac{\partial B}{\partial x} g^{\prime}\right)-\frac{r}{\alpha} \frac{\partial B}{\partial x}
$$

Appendix G shows that the isocline (38) defines a relationship

$$
x_{t}=d\left(N_{t}\right)
$$

as depicted in Figure 13. 
Appendix G shows that the d curve would coincide with the o curve defined by (12) in the steady-state analysis if the discount rate were zero. With $\boldsymbol{r}>\boldsymbol{0}$, by contrast, exploitation over the isocline (38) is higher than the exploitation given by (12):

$$
\mathrm{d}\left(\mathrm{N}_{\mathrm{t}}\right)>\mathrm{o}\left(\mathrm{N}_{\mathrm{t}}\right)
$$

By definition, the steady-state in which both environmental quality and exploitation are unchanged over time is obtained when the two isoclines cross; this steady-state is denoted by $\left(N^{*}, x^{*}\right)$ in Figure 13 .

\section{Convergence to Long-Run Steady State and Stability}

Figure 13 further shows the phase-diagram analysis of the welfare-maximizing trajectories of the level of natural capital and its exploitation around the steadystate exploitation $\left(N^{*}, x^{*}\right)$. These trajectories are indicated by the dark arrows in each area around the $\mathrm{g}$ and $\mathrm{d}$ isoclines. These trajectories imply that the long-run dynamics of the system is saddle-path stable. In a neighbourhood of the steady state, the system converges to the latter following the red stable arm.

Figure 13. Welfare-maximizing exploitation (optimal converging trajectories)

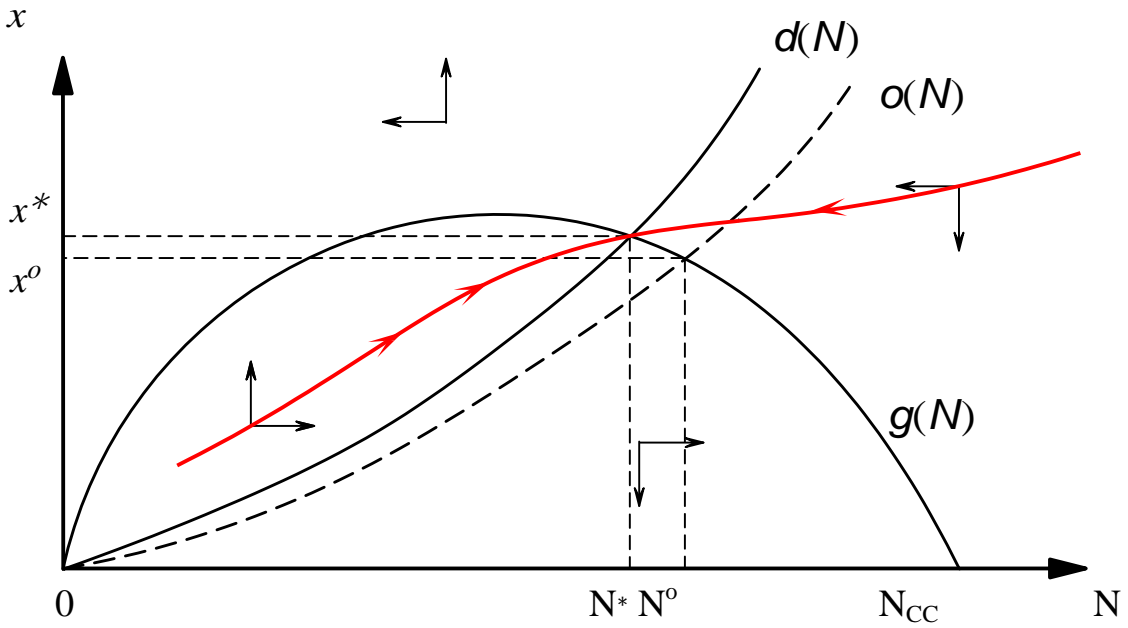

Result 9 (Welfare-maximizing transitional dynamics and long-run steady state) In the welfare-maximizing exploitation with an optimal transitional dynamics, the exploitation converges to a long-run, stable steady state.

This result confirms that the steady-state analysis of Sections 1.3 and 1.4 is relevant in a long-run perspective: Absent any steady-state restriction, the exploitation turns out to be sustainable. That being said, the long-run welfare-maximizing steady-state with a transitional dynamics slightly differs from the welfare-maximizing sustainable steady state of Section 1.3.1. This is due to discounting.

\section{Social Discounting}

The long-run steady-state exploitation $\left(N^{*}, x^{*}\right)$ corresponds to the intersection of the $g$ and $d$ curves. Since $d\left(N_{t}\right)>o\left(N_{t}\right)$, it turns out that $N^{*}<N^{o}$. 
Result 10 (Welfare-maximizing long-run steady state and social discounting) Due to the discounting rate $r>0$, the welfare-maximizing exploitation with an optimal transitional dynamics, the natural capital is less conserved than in the welfaremaximizing steady-state exploitation: $N^{*}<N^{o}$.

This result and its intuition is standard. Assume, for example, that the initial level of natural capital is below the long-run level targeted by the social planner. When the longrun steady-state is reached progressively along a transition path, rather than immediately, the short-run transition requires that the capital be exploited less than its natural growth so that it increases. Social discounting reflects society's impatience: The transition is a sacrifice in terms of social welfare, which calls for a downward adjustment of the longrun steady-state level of natural capital to alleviate the sacrifice.

\subsubsection{Competitive Equilibrium without Public Policy}

Let us now extend the case of the competitive market equilibrium of Subsection III.B to allow a transitional dynamics. As the previous extension of the welfare-maximizing problem shows, the presence of a transitional dynamics gives rise to the influence of discounting.

As far as discounting is concerned, not only the interest rate is relevant to competitive operators, but also their expectations to continue their exploitation of the site in the future. Many operators, for example in the tourism industry, are multinational and mobile.

Assume, for simplicity, that the representative competitive firm of the industry anticipates that, at each date $t \geq 0$, there is a constant probability $0 \leq \gamma<1$ that it will not operate anymore in the industry from this date on. The existence of this probability implies a "short-termism" of firms, which is formally equivalent to discounting. In this case, the problem of the industry is modified to become

$$
\max _{\left(x_{t}\right)} \int_{t \geq 0}^{\infty}\left(p_{t} x_{t}-C\left(x_{t}\right)\right) e^{-(r+\gamma)^{t}} d t
$$

where $p_{t}$ is taken as given at the level $p_{t}=\partial U / \partial x$ established by the market, like in (13), and $r+\gamma$ is the industry's effective discount rate.

\section{Convergence to Long-Run Steady State and Stability}

In this context, the condition for the maximization of profits (41) is the same as in the steady-state analysis of Subsection III.B, and defines the same function

$$
x_{t}=e\left(N_{t}\right)
$$

relating the prevailing level of natural capital and the profit-maximizing exploitation. It follows that there is a steady-state competitive exploitation, which is characterized by the intersection of the $e$ curve with the $g$ curve at point $\left(N^{e}, x^{e}\right)$, as depicted in Figure 14.

Outside this steady state, the economy converges to it, along the $\boldsymbol{e}$ curve, at the speed given by the dynamic equation (35). The following result follows. 
Result 11 (Competitive-equilibrium transitional dynamics and long-run steady state) In the competitive-equilibrium exploitation with an optimal transitional dynamics, the exploitation converges to a long-run, stable steady state, which is identical to the sustainable competitive-equilibrium exploitation $\left(N^{e}, x^{e}\right)$.

The result confirms that the steady-state analysis of Sections 1.3 and 1.4 is relevant in a long-run perspective. It is even more so in the competitive case, in which the long-run steady-state equilibrium following the short-run transition is exactly identical to the sustainable exploitation identified in the steady-state analysis.

Figure 14. Competitive exploitation (optimal converging trajectories)

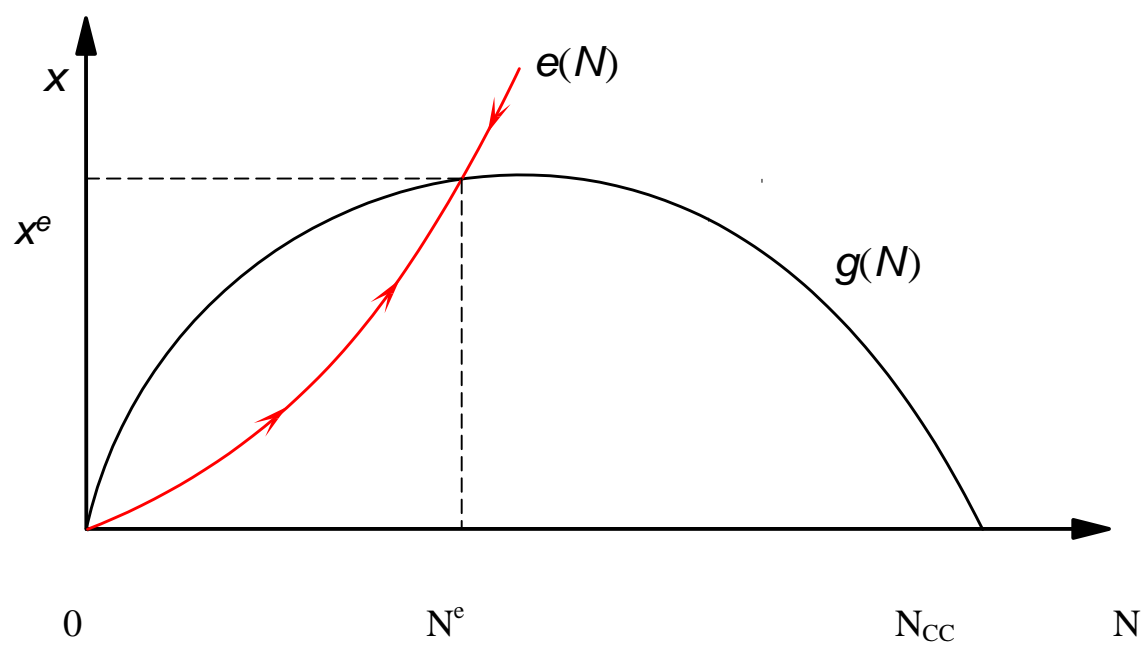

\section{Industry Short-Termism}

It follows from the previous subsection that discounting is irrelevant in the competitive equilibrium.

Result 12 (Competitive equilibrium, discounting and firms' short-termism) The discounting rate $r$ and the parameter $\gamma$ reflecting firms' short-termism affect neither the competitive-equilibrium long-run steady state $\left(N^{e}, x^{e}\right)$ nor the short-run transition towards this steady state.

When the industry is competitive and its operators do not take into the dynamic impact of their exploitation on environmental quality as per (35), its problem has no dynamic dimension, unlike the welfare-maximizing problem. As a result, the competitiveequilibrium exploitation is independent of discounting, whether it is due to the interest rate or to short-termism.

This result would not carry over to the case of an industry which - at least partly - takes into account the law of motion of the natural capital (35). Everything else being held unchanged, such an industry would induce more conservation in the long run. However, as its effective discount rate $r+\gamma$ would increase, it would become closer to the competitive industry examined here and its long-run exploitation would tend to $\left(N^{e}, x^{e}\right)$. 


\subsection{Executive Summary}

This section enumerates the main lessons from the paper's analysis.

- An industry, e.g. the tourism sector, relies on a productive natural capital, e.g. the environmental quality of natural sites, when its activity consists in exploiting the natural capital in such a way that it deteriorates the conditions in which the industry will operate in the long run.

- The welfare-maximizing management of a productive natural capital requires that the long-run opportunity cost of short-run exploitation be taken into account.

- The welfare-maximizing management of a productive natural capital does not maximize the sustainable exploitation of the capital; it induces more conservation than the maximum sustainable exploitation does.

- When the welfare-maximizing exploitation is implemented, it generates an economic rent besides ordinary profits which may accrue to the industry, or be taxed away by public policy.

- Competition with no public policy induces

- less conservation of the natural capital and a lower price for the good or service produced by the industry than in the welfare-maximizing equilibrium;

- $\quad$ the exploitation rent to vanish.

- The welfare-maximizing sustainable exploitation can be implemented by using a corrective exploitation tax that reflects the long-run opportunity cost of exploitation; in that case, the tax captures the exploitation rent and its distributional consequences only depend on how this tax proceed is rebated, but not at all on whether the tax is imposed on firms or consumers.

- By contrast, restricting the industry's exploitation at the sustainable welfaremaximizing level does not guarantee that the natural capital's conservation be sufficient, but if exploitation restrictions are accompanied by measures to directly protect the natural capital.

- An industry that exerts its monopoly power tends to induce more conservation of the natural capital than under competition, but does not necessarily reduce exploitation.

- A regulator that is concerned about the sustainable-exploitation profits of the industry should command that the natural capital be exploited less and conserved more.

- A regulator that is concerned with the collection of tax revenues should tax the exploitation of the natural capital at a higher rate than the output of an otherwisesimilar sector that does not rely on a productive natural capital; doing so, it would induce less exploitation and more conservation. 
- A higher social discount rate justifies more exploitation and less conservation of the natural capital.

- Competitive firms' "short-termism" is irrelevant when these firms do not take into account the long-run opportunity cost of their exploitation; it would only be relevant if firms were taking this opportunity cost into account, inducing them to conserve less of the natural capital. 


\section{References}

Arnason, R. (2017), "Efficient Pricing of Tourist Sites," mimeo, Faculty of Economics at University of Iceland.

Baron, D.P., and R.B. Myerson (1982), "Regulating a Monopolist with Unknown Costs,"

Econometrica, 50: 911-930.

Clarke, H.R. (1993), "Tourism, Economic Welfare and Efficient Pricing," Annals of Tourism Research, 20: 613-632.

Costello, C., N. Qu'erou, and A. Tomini (2015), "Partial Enclosure of the Commons,"

Journal of Public Economics, 121: 69-78.

Granquist, S.M., and H. Sigurjonsdottir (2014), "The Effect of Land Based Seal Watching Tourism on the Haul-Out Behaviour of Harbour Seals (Phoca Vitulina) in Iceland," Applied Animal Behaviour Science, 156: 85-93.

Hiriart, Y., and D. Martimort (2012), "How Much Discretion for Risk Regulators," RAND Journal of Economics, 43: 283-314.

Jensen, F., J.B. Jacobsen, N. Strange, and B.J. Thorsen (2014), "Wildlife Reserves, Populations, and Hunting Outcome with Smart Wildlife", Natural Resource Modeling, 27: 376-395.

Lindberg, K. (1991), "Policies for Maximizing Nature Tourism's Ecological and Economic Benefits," International Conservation Financing Project Working Paper, World Resources Institute.

OECD (2017), Economic Surveys: Iceland 2017.

Ramsey, F.P. (1927), “A Contribution to the Theory of Taxation,” Economic Journal, 37: 47-61.

Regev, U., A.P. Gutierrez, S.J. Schreiber, and D. Zilberman (1998), "Biological and Economic Foundations of Renewable Resource Exploitation," Ecological Economics, 26: 227-242.

Schaefer, M.B. (1954), "Some Aspects of the Dynamics of Populations Important to the Management of Commercial Marine Fisheries," Inter-American Tropical Tuna Commis- sion, Bulletin 1: 27-56.

Solow, R.M. (1974), "The Economics of Resources or the Resources of Economics," Amer- ican Economic Review, 64: 1-14.

Zilberman, D. (2014), "The Economics of Sustainable Development," American Journal of Agricultural Economics, 96: 385-396. 


\section{MATHEMATICAL APPENDICES}

Results that are not shown in these appendices are established in the main text.

\section{A. Proof of Result 1}

The Lagrangian function associated with the maximization of (7) under the sustainability constraint (8) is

$$
B(x, N)-\lambda(x-g(N))
$$

where $\lambda$ denotes the multiplier associated with the constraint. The necessary first-order conditions for the choice of $x$ and $N$ are given by conditions (9) and (10) respectively, where $\lambda^{o}$ indicates the value of the multiplier at the solution. Substituting the expression of $\lambda^{o}$ given by (9) into (10) yields the necessary condition (11).

Condition (11) is a Cartesian equation in which the left-hand side is continuously differentiable by assumption. Therefore, it implicitly defines a continuous functional relation between $N$ and $x$, defined as the o function of (12). Clearly, $0=o(0)$. For $N>0$, the total differentiation of (11) with respect to $N$ and $\boldsymbol{x}$ shows that, along the $o$ function,

$$
\frac{d x}{d N}=\frac{-\left[\frac{\partial^{2} B}{\partial N^{2}}+\alpha g^{\prime}+\frac{\partial B}{\partial x} g^{\prime \prime}\right]}{\alpha+\frac{\partial^{2} B}{\partial x^{2}} g^{\prime}}
$$

The main text has explained that $g^{\prime}$ is strictly negative at the intersection of the $o$ curve with the $g$ curve, which, therefore, occurs over $N>N_{M S E}$. Moreover, the examination of the above expression of the $o$ curve's slope $d x / d N$ reveals that the latter curve is strictly increasing for all $N>N_{M S E}$, i.e., such that $g^{\prime}<0$. It follows that the o function is strictly increasing in a neighbourhood of its intersection at $N o>N_{M S E}$, and that this intersection is unique.

\section{B. Proof of Result 2}

In the same way as in Appendix A, the Lagrangian function associated with the maximization of (14) under the sustainability constraint (8) is

$$
p x-C(x)-\lambda(x-g(N))
$$

Since the price is taken as independent of the exploitation quantity, the first-order condition for the choice of $x$ is $p-C^{\prime}(x)=\lambda$. The first-order condition for the choice of $N$ 
is $\alpha x+\lambda g^{\prime}=0$, where $\alpha x=\partial B / \partial N$ by assumption. Combining these necessary conditions by substituting $\lambda$, one obtains that the sustainable exploitation by the sole competitive owner of the natural capital is characterized by the same condition (11) as the social planner's solution and, therefore, is identical to this solution $\left(N^{o}, x^{o}\right)$. This also implies that the value of the multiplier is the same $\lambda^{o}$ in both cases. Replacing this value and the price (13) evaluated at the solution in the above first-order condition for the choice of $x$, one finds $\partial U\left(x^{\boldsymbol{o}}, N^{\boldsymbol{o}}\right) / \partial x-C^{\prime}(x o)=\lambda^{\boldsymbol{o}}$.

\section{Proof of Result 3}

The first-order condition for the maximization of (15) with respect to $x$ is the standard condition $p=C^{\prime}(x)$ where $p$ is given by (13). This can be rewritten as (16), which defines the relationship between $x$ and $N$ denoted by the $e$ function in (17).

One can compare the e function with the $o$ function by comparing the functions that implicitly define them. $o$ satisfies the equality $\partial B / \partial x=\lambda^{o}>0$, while e is defined by $\partial B / \partial x=0$. Let us examine the more general relationship between $\partial B / \partial x=\chi$, where $\chi \geq 0$, encompassing both functions. Since $\partial B / \partial x$ is decreasing in $\mathrm{x}$, an increase in $\chi$ holding $N$ unchanged must imply a decrease in $x$. It follows that, for any $N,(18)$ is observed.

\section{Proof of Result 6}

In the same way as for functions $o$ and $e$, condition (22) implicitly defines a relationship between $N$ and $x$ that can be expressed as the functional relationship $x=m(N)$.

Given that the function $m$ satisfies an equality between $\partial B / \partial x$ and a strictly positive value, the analysis of the Proof of Result 3 applies, from which it follows that for any $N, m(N)$ $<e(N)$.

\section{E. Proof of Result 7}

The Lagrangian function associated with the problem of maximizing (25) under constraint (8) is

$$
U(x, N)-(1+\beta) C(x)+\beta\left(\frac{\partial U}{\partial x} x-\lambda(x-g(N)) .\right.
$$

The first-order conditions for the choice of $x$ and $N$ are respectively $\partial U / \partial x+(1+\beta) C^{\prime}(x)-$ $\beta x \partial^{2} U / \partial x^{2}-\beta \partial U / \partial x=\lambda$ and $\partial U / \partial N+\beta \alpha x+\lambda g^{\prime}=0$. Combining these two conditions by replacing $\lambda$ and using that, by assumption, $\alpha x=\partial B / \partial N$, one can obtain the necessary condition (26).

In the same way as for condition (11) and function $o$, condition (26) defines a relationship between $N$ and $x$ that is denoted by the function $b$. One can compare functions $o$ and $b$ by comparing (11) with (26). For simplicity, our analysis focuses on arbitrarily small values of $\beta$, i.e., as explained in the main text, on a neighbourhood of the optimum sustainable exploitation $\left(N^{o}, x^{o}\right)$. It has been established that in such a neighbourhood, $g^{\prime}<0$.

Therefore, (26) satisfies the equality $\partial B / \partial N+g^{\prime} \partial B / \partial x=\sigma$ for some $\sigma<0$ whereas (11) satisfies the same equality with $\sigma=0$. As long as $g^{\prime}<0$, the left-hand side of the equality 
is increasing with $x$. It follows that, for a given $N$, the equality with $\sigma<0$ determines a lower $x$ so that $b(x)<o(x)$.

\section{F. Proof of Result 8}

The problem of maximizing (30) subject to (8) can be reformulated in terms of the single equilibrium variable by using constraint $(8)$ to replace $\tilde{x}$ by $g(\widetilde{N})$. This way, the problem becomes the maximization of $B(g(\widetilde{N}), \widetilde{N})+\delta \tau g(\widetilde{N})$ by choice of $\boldsymbol{\tau}$. Differentiating the reformulated objective with respect to $\tau$ and setting the obtained derivative equal to zero, one obtains the necessary first-order condition which, after rearranging, becomes

$$
\frac{\partial B}{\partial N}+g^{\prime} \frac{\partial B}{\partial x}=-\delta\left[\frac{g(N)}{\frac{d \widetilde{N}}{d \tau}}+\tau g^{\prime}\right]
$$

Using again $\tilde{x}=g(\widetilde{N})$, and its implication that $\frac{d \tilde{x}}{d \tau}=g^{\prime} d \widetilde{N} / d \tau$ condition (31) follows. This condition implicitly defines the relationship between $\widetilde{N}$ and $\tilde{x}$ that is denoted by the $f$ function in (32).

The analysis focuses on arbitrarily small values of $\delta$, i.e., on a neighbourhood of the optimum sustainable exploitation $\left(N^{o}, x^{o}\right)$. This implies that $g^{\prime}<0$. Note, moreover, that a positive tax would only be implemented if it was raising more tax revenues than a zero tax. Therefore, a tax is only implemented in situations in which

$$
\frac{d(\tau \tilde{x})}{d \tau}=\tau \frac{d \tilde{x}}{d \tau}+\tilde{x}>0
$$

In this context, one can easily verify that the right-hand side of (31) is strictly negative. The analysis of $\partial B / \partial N+g^{\prime} \partial B / \partial x=\sigma$ in the Proof of Result 7 applies to the comparison of the $\mathrm{f}$ and o functions; it immediately implies that $f(\widetilde{N})<0(\widetilde{N})$.

Consider now the optimum tax rate that implements the solution examined above.

Rearranging condition (31) by using the definition $B(\tilde{x}, \widetilde{N})=U(\tilde{x}, \widetilde{N})-C(\tilde{x})$, and the equality $\partial U / \partial x-C^{\prime}=\tau$ that follows from the market equilibrium condition (29), one obtains

$$
\tau g^{\prime}(1+\delta)=-\delta g^{\prime} \frac{\tilde{x}}{\frac{d \tilde{x}}{d \tau}}-\frac{\partial U}{\partial N}
$$

from which (33) is derived.

\section{G. Proof of Results 9 and 10}

The Hamiltonian function associated with the intertemporal problem of maximizing (34) under the dynamic constraint (35) is

$$
B\left(x_{t}, N_{t}\right) e^{-r t}+\lambda_{t}\left(g\left(N_{t}\right)-x_{t}\right)
$$


where $\lambda_{t}$ is the co-state variable associated with the dynamic constraint. By the Maximum Principle, one obtains the three following necessary conditions. First, the first-order condition for the choice of $x_{t}$,

$$
\frac{\partial B}{\partial x} e^{-r t}=\lambda_{t}
$$

Second, the optimal law of motion of the co-state variable:

$$
\lambda_{t}=-\frac{\partial B}{\partial N_{t}} e^{-r t}-\lambda_{t} g^{\prime}
$$

Third, the growth constraint (35). Differentiating the first condition with respect to time, combining it with the second one by replacing $\lambda_{t}$ and $\dot{\lambda}_{t}$, and rearranging, one obtains equation (37). Setting $\dot{x}_{t}$ to zero in this equation and rearranging, the expression of the isocline (38) follows.

In the same way as for other relationships between $\boldsymbol{N}$ and $\boldsymbol{x}$ before, (38) defines implicitly the functional relationship $d$ in (39).

(38) may be rewritten

$$
\frac{\partial B}{\partial N_{t}}+g^{\prime} \frac{\partial B}{\partial x_{t}}=\alpha\left(x_{t}-g\left(N_{t}\right)\right)+r \frac{\partial B}{\partial x}
$$

Integrating the sustainability relationship $x_{t}=g\left(N_{t}\right)$ to this condition, as in the steadystate analysis, it would coincide with (11) that defines the o function if $r$ were zero. Under the same conditions with $r>0$, the analysis of $\partial B / \partial N+g^{\prime} \partial B / \partial x=\sigma$ in the Proof of Result 7 applies and shows (40).

One can verify that that combining equations (38) and (36) of the isoclines, one obtains

$$
\frac{\partial B}{\partial N}+\frac{\partial B}{\partial x} g^{\prime}(N)=r \frac{\partial B}{\partial x}
$$

which is strictly positive because $r>0$, rather than zero in the steady-state analysis. 